\title{
Angewandte
}

Supporting Information

\section{DNA Origami Rotaxanes: Tailored Synthesis and Controlled Structure} Switching

John T. Powell, Benjamin O. Akhuetie-Oni, Zhao Zhang, and Chenxiang Lin*

anie_201604621_sm_miscellaneous_information.pdf 


\section{Contents}

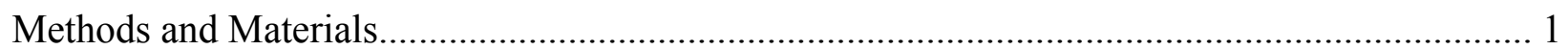

DNA origami design and preparation........................................................................ 1

Calculation of dL and dS ssDNA tendon length and force............................................... 1

Multimeric assemblies and macrocycle reconfiguration................................................. 2

Transmission Electron Microscopy ………………….................................................. 2

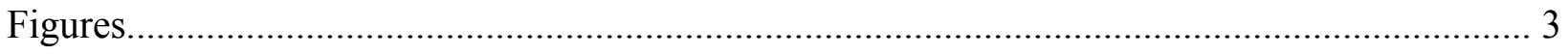

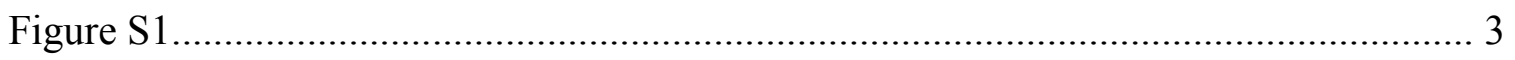

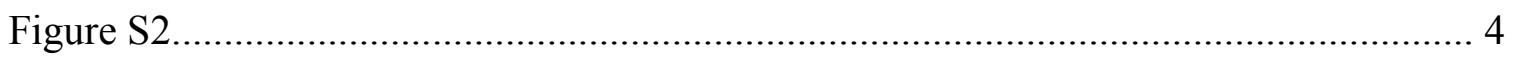

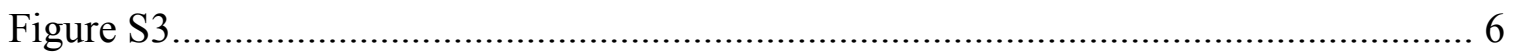

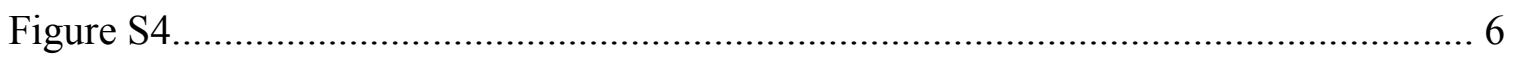

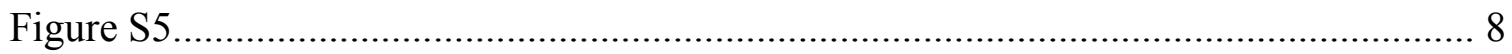

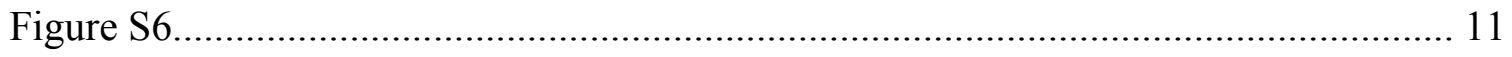

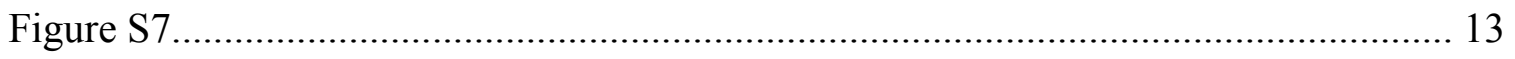

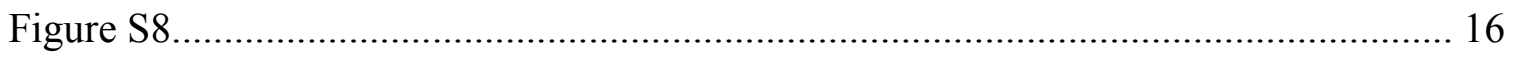

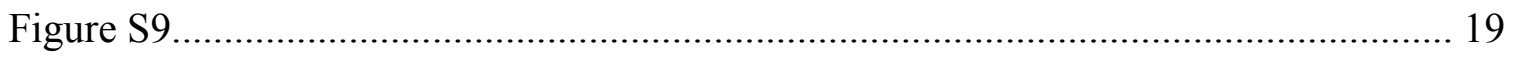

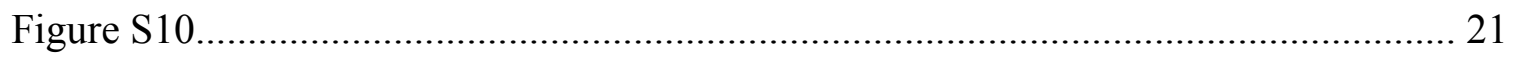

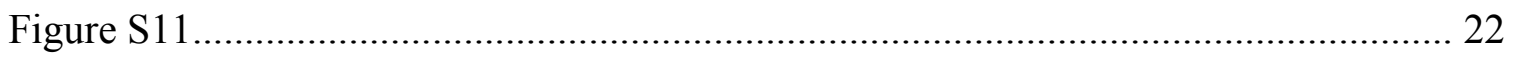

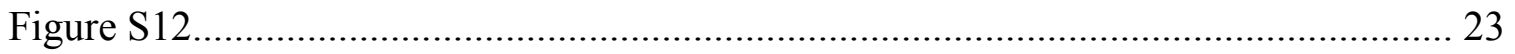

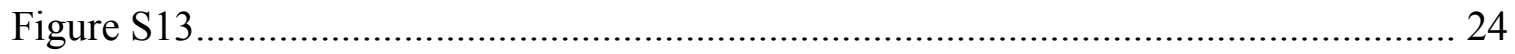

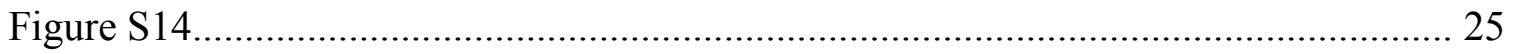

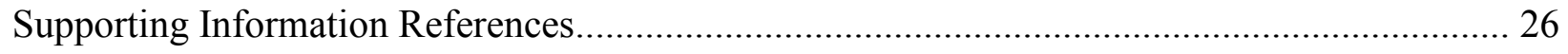




\section{Methods and Materials}

\section{DNA origami design and preparation}

The DNA rings were designed in caDNAno (Figure S1). All staple strands were purchased from Integrated DNA Technologies, Inc. within 96-well plates and with concentrations normalized to $100 \mu \mathrm{M}$. Scaffold strands p7308 and p8064 are variants of $\mathrm{m} 13 \mathrm{mp} 18$ singlestranded DNA and produced using phages and E.coli strains as described before. ${ }^{1,2}$

Monomers dL and dS were assembled from p7308 scaffold strand (50 nM) and a pool of staple strands (400 $\mathrm{nM}$ each) in $1 \times \mathrm{TE}-\mathrm{Mg}^{2+}$ buffer $(5 \mathrm{mM}$ Tris $\bullet \mathrm{HCl}, 1 \mathrm{mM}$ EDTA, $12.5 \mathrm{mM}$ $\left.\mathrm{MgCl}_{2}, \mathrm{pH} 8.0\right)$, using a 36-hour annealing program $\left(80-65{ }^{\circ} \mathrm{C},-1{ }^{\circ} \mathrm{C} / 5 \mathrm{~min} ; 64-24{ }^{\circ} \mathrm{C},-1{ }^{\circ} \mathrm{C} / 50\right.$ min; $15^{\circ} \mathrm{C}$ hold). Monomers $\mathrm{M}$ and $\mathrm{M}_{\text {Short }}$ were assembled from p8064 scaffold strand (50 $\mathrm{nM}$ ) and a pool of staple strands (300 $\mathrm{nM}$ each) in $1 \times \mathrm{TE}-\mathrm{Mg}^{2+}$ buffer, using the same 36-hour annealing program. Typically, $1000 \mu \mathrm{l}$ of assembly product were concentrated to $200 \mu \mathrm{l}$ using Amicon Ultra-0.5 mL Centrifugal Filters (EMD Millipore) with 30-kD nominal molecular weight limit (NMWL), loaded on top of a $15-45 \%(\mathrm{v} / \mathrm{v})$ quasi linear glycerol gradient in a polycarbonate centrifuge tube $(13 \times 51 \mathrm{~mm}$, Beckman Coulter Inc.), and spun at $50 \mathrm{krpm}$ for 120 minutes (Table S1) on a Beckman SW-55-Ti rotor. The contents of the tube were fractionated from top to bottom ( $200 \mu \mathrm{L}$ per fraction). Generally, $5 \mu \mathrm{L}$ of each fraction was loaded onto a $1.5 \%$ agarose gel containing $0.5 \mu \mathrm{g} / \mathrm{mL}$ ethidium bromide and run in $0.5 \times \mathrm{TBE}, 10 \mathrm{mM} \mathrm{MgCl} 2$ for 2 hours at $5 \mathrm{~V} / \mathrm{cm}$. The fractions containing well-formed monomeric DNA origami were combined and concentrated using Amicon Ultra-0.5 mL Centrifugal Filters with 30-kD NMWL. Origami concentrations were determined using a NanoVue Plus Spectrometer (GE Healthcare). The concentrated monomers were stored in $1 \times \mathrm{TE}-\mathrm{Mg}^{2+}$ buffer at $4{ }^{\circ} \mathrm{C}$.

\section{Calculation of $\mathrm{dL}$ and $\mathrm{dS}$ ssDNA tendon length and force}

Led by the example of prior DNA origami prestressed tensegrity nanodevices ${ }^{3}$, we designed the dL/dS DNA origami monomer with eight ssDNA tendons attaching the stopper to the axle. Each ssDNA tendon exerts a tension force of $\sim 6 \mathrm{pN}$, and the combined and opposing forces exerted by these four tendon pairs hold the stopper centered about its axle. The ssDNA length required to produce a $6-\mathrm{pN}$ force between the axle and the stopper of each half-dumbbell monomer was predicted by modeling each ssDNA as a freely-jointed chain polymer. Guided by the following Python ( $\mathrm{v}$ 2.7.10) script, we chose an ssDNA length of 35 nucleotides, corresponding to $5.7 \mathrm{pN}$ when stretched over the $9.8 \mathrm{~nm}$ between the axle and inner surface of the stopper.

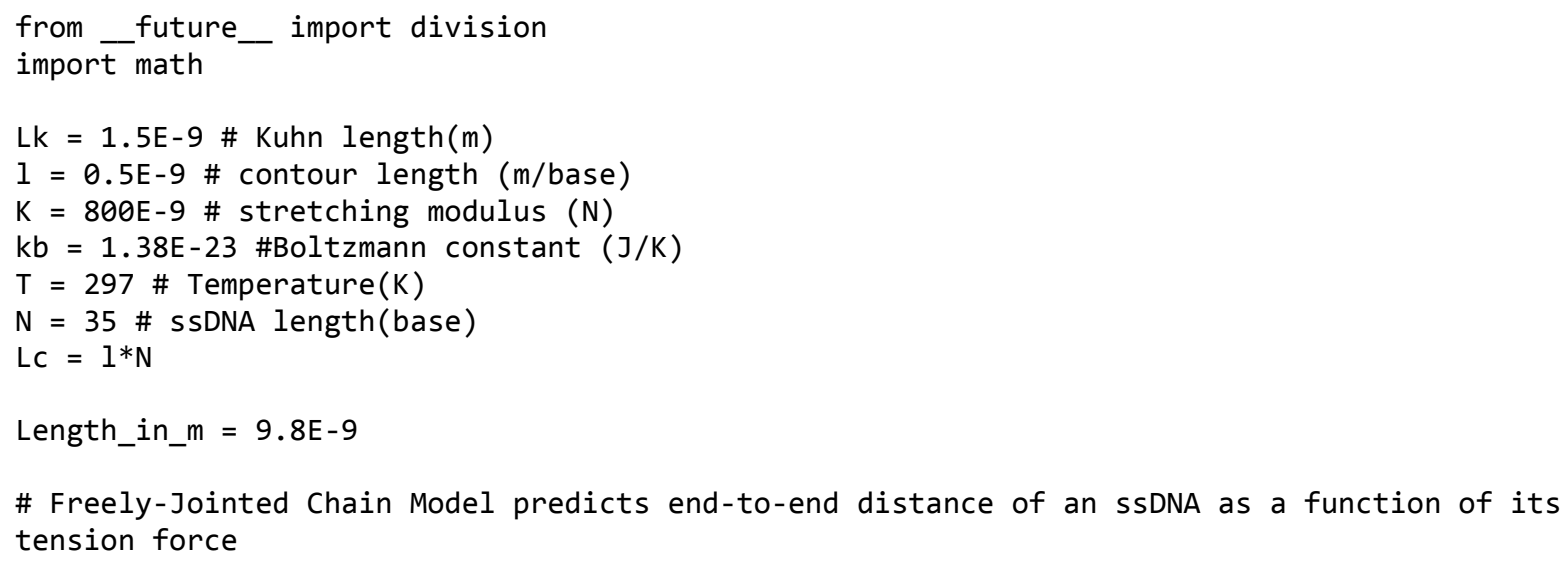




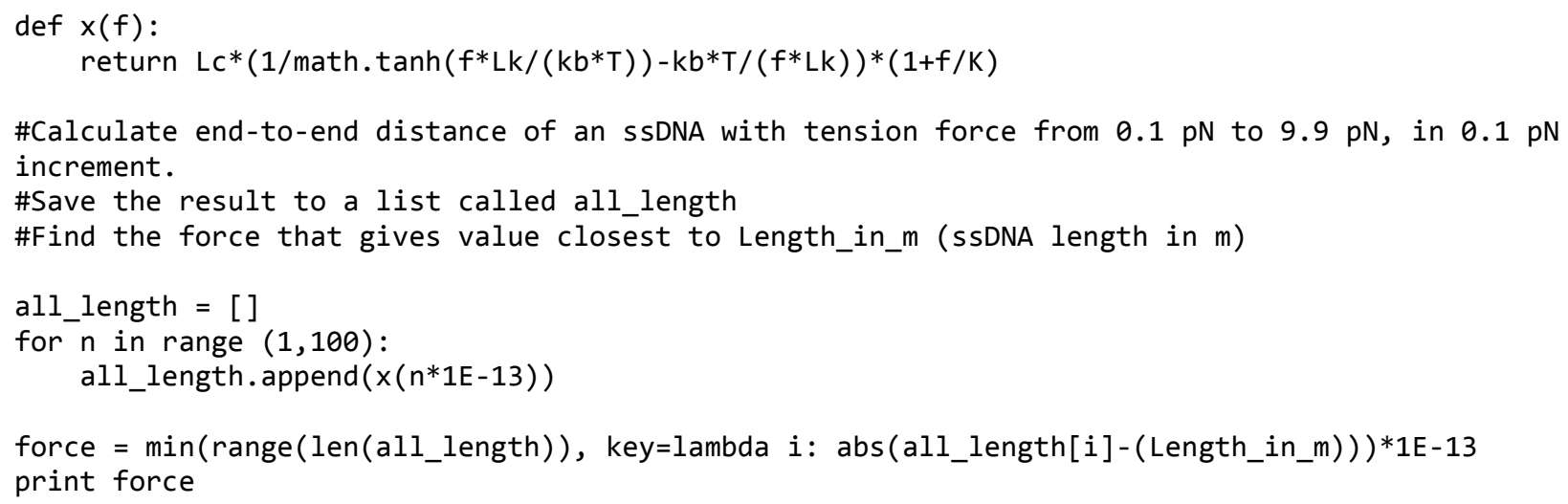

\section{Multimeric assemblies and macrocycle reconfiguration}

The assembly reactions for $\mathrm{D}$, ModL, ModS, $\mathrm{pR}(\operatorname{ModL})$, and $\mathrm{pR}(\operatorname{ModS})$ were carried out with the same general conditions: DNA origami components were mixed at equal molar ratios in $1 \times \mathrm{TE}-\mathrm{Mg}^{2+}$ buffer and incubated at $40{ }^{\circ} \mathrm{C}$ for 16 hours. In the case of $\mathrm{dL}$ and $\mathrm{dS}$ docking to $\mathrm{M}$ and $\mathrm{M}_{\text {short, }}$, each of these incubations also included 60 -fold excess of either $\mathrm{X}$ or $\mathrm{Y}$ linking oligonucleotides. The concentration of each monomer in a typical dimerization reaction was 4-8 $\mathrm{nM}$. Displacement of $\mathrm{M}$ and $\mathrm{M}_{\text {short }}$ from $\mathrm{dL}$ or $\mathrm{dS}$ was performed by adding 5-fold excess of $\mathrm{X}^{\prime}$ or $\mathrm{Y}^{\prime}$ displacing strands relative to the $\mathrm{X}$ or $\mathrm{Y}$ oligonucleotides, respectively, and incubating at $44{ }^{\circ} \mathrm{C}$ for $12-16$ hours. Reconfiguration of $\mathrm{M}_{\text {short }}$ was achieved by adding 20-fold excess of pillar staple strands to $\mathrm{M}_{\text {short }}$ or $\mathrm{R}\left(\mathrm{M}_{\text {short }}\right)$ and annealing from $40{ }^{\circ} \mathrm{C}$ to $20^{\circ} \mathrm{C}$ over 18 hours.

\section{Transmission Electron Microscopy}

For negative-stain transmission electron microscopy (TEM), a drop of sample $(4 \mu \mathrm{L})$ was deposited on a glow discharged formvar/carbon coated copper grid (Electron Microscopy Sciences), incubated for 1 minute, and blotted away. The grid was then washed briefly and stained for 1 minute, in both cases with $2 \%(\mathrm{w} / \mathrm{v})$ uranyl formate. Images were acquired on a JEOL JEM-1400Plus microscope (acceleration voltage: $80 \mathrm{kV}$ ) with a bottom-mount $4 \mathrm{k} \times 3 \mathrm{k}$ CCD camera (Advanced Microscopy Technologies). 

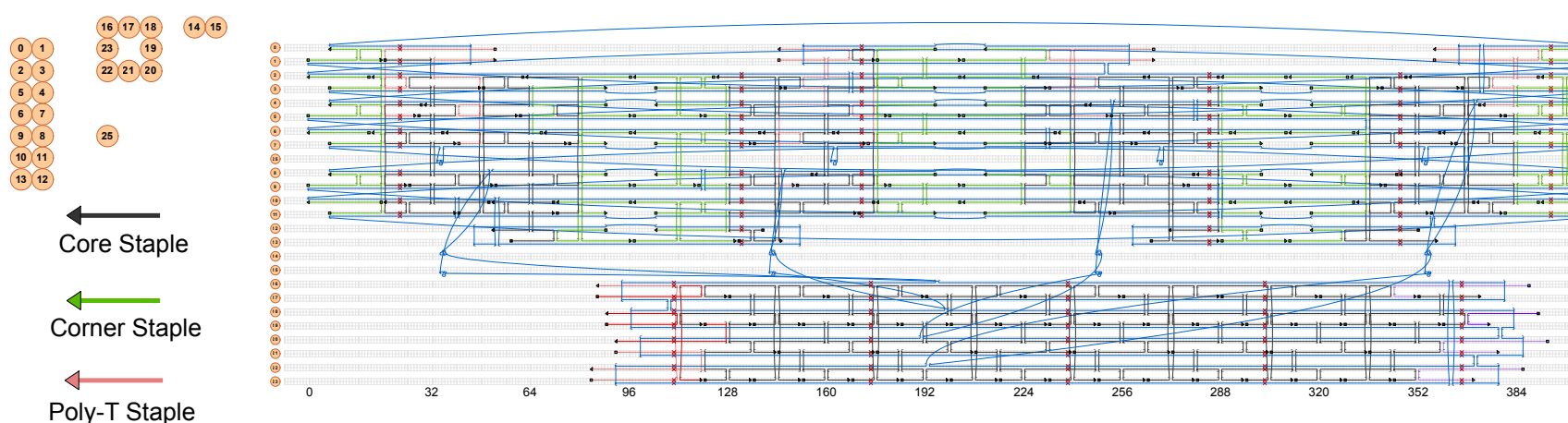

dS

Poly-T Staple

Sticky-end Staple
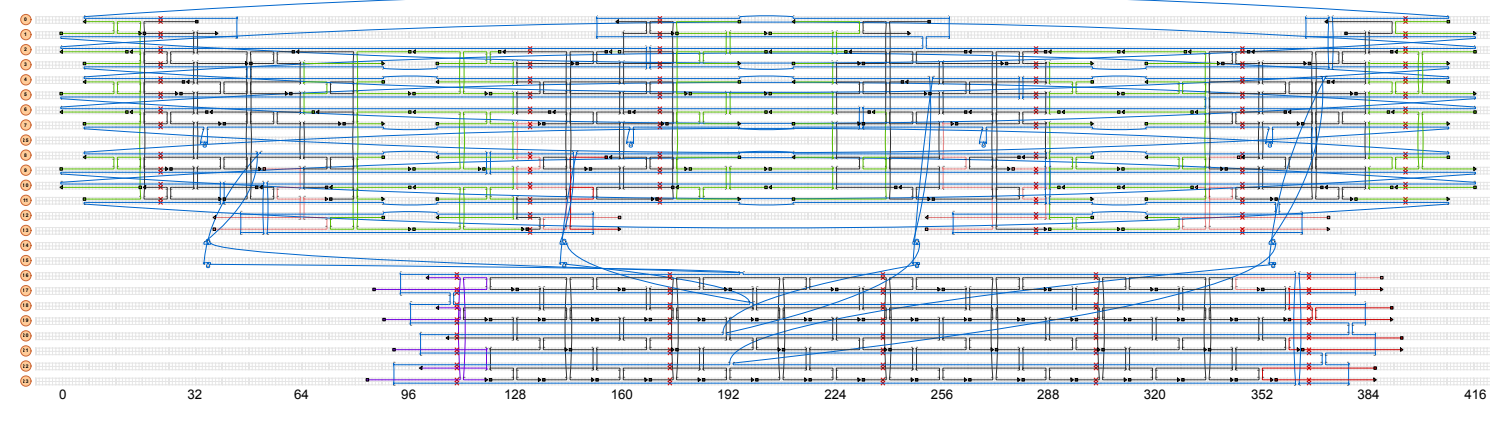

$\mathrm{dL}$

Figure S1-1. CaDNAno designs of $\mathrm{dS}$ and $\mathrm{dL}$ DNA origami monomers. Note the $\mathrm{dT}_{8}$ extensions at the end of axle and notches to prevent blunt-end stacking.
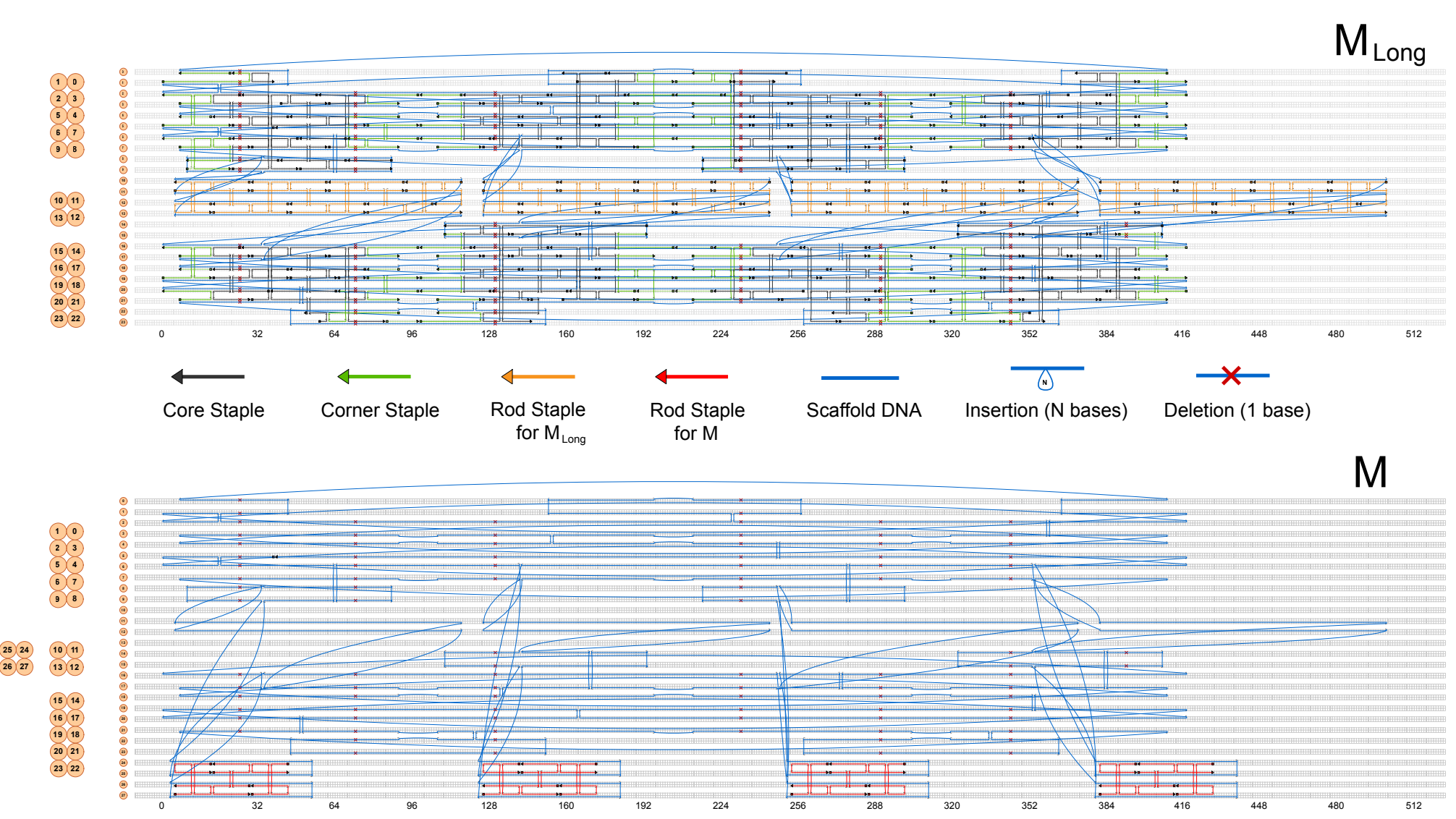

Figure S1-2. CaDNAno design of $\mathrm{M}_{\text {Long }}$ and M DNA origami monomers. All staples except "Rod Staples for $\mathrm{M}_{\text {Long }}$ " and "Rod Staples for M" are shared between designs. 

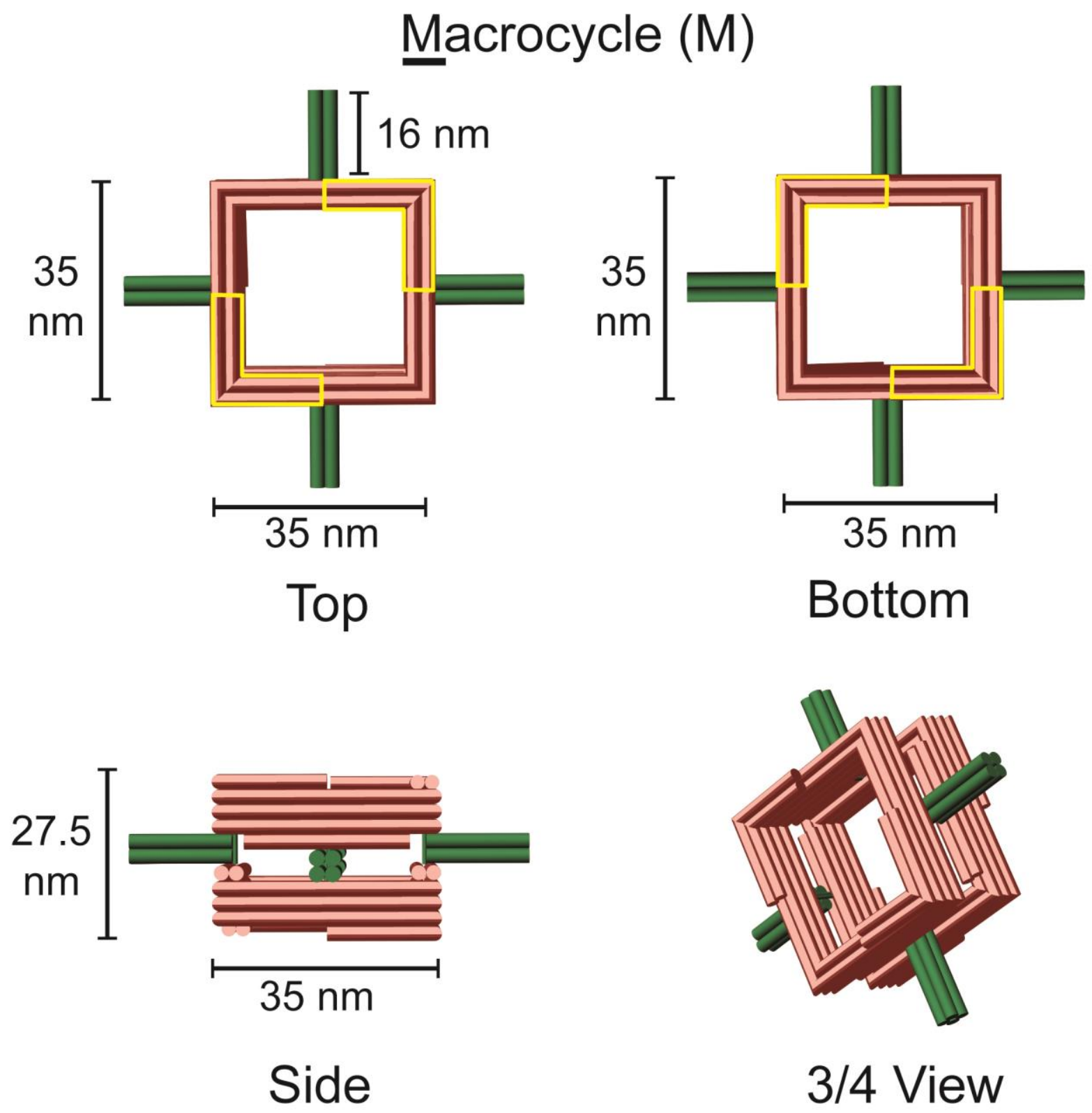

Figure S2-1. Schematic drawings for various views of the macrocycle M monomer. Notched surfaces used for dimerization with $\mathrm{dL}$ or $\mathrm{dS}$ are highlighted in yellow on top and bottom views. 


\section{Half-dumbbell with Long or Short inert end (dL or dS)}

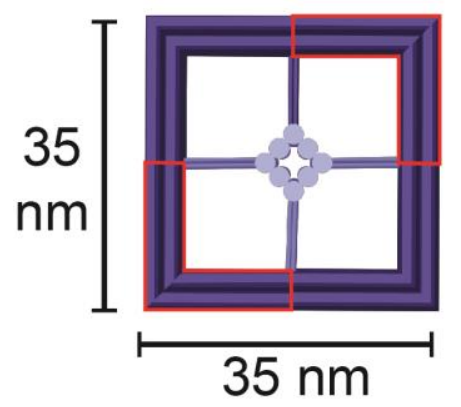

Top

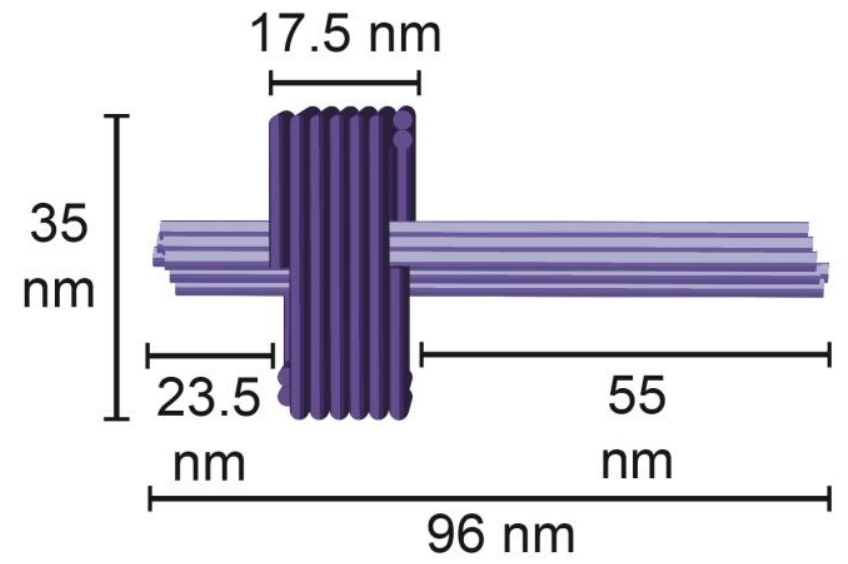

Side

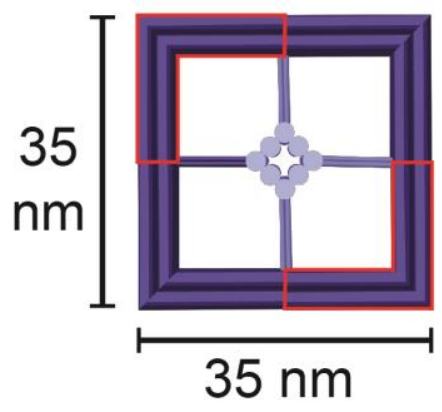

\section{Bottom}

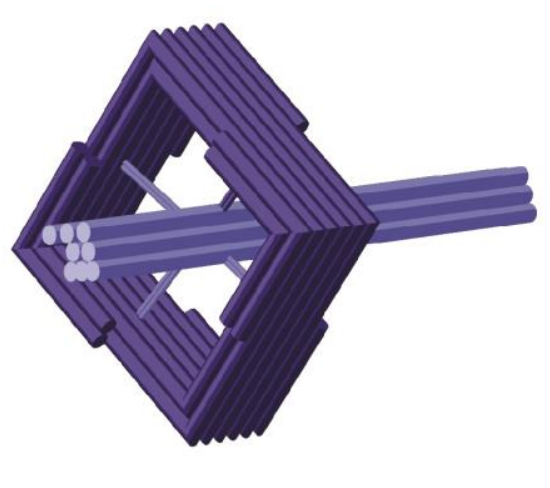

3/4 View

Figure S2-2. Schematic drawings for various views of the half-dumbbell dL and dS monomers. Notched surfaces used for dimerization with $\mathrm{M}$ are highlighted in red on top and bottom views. 


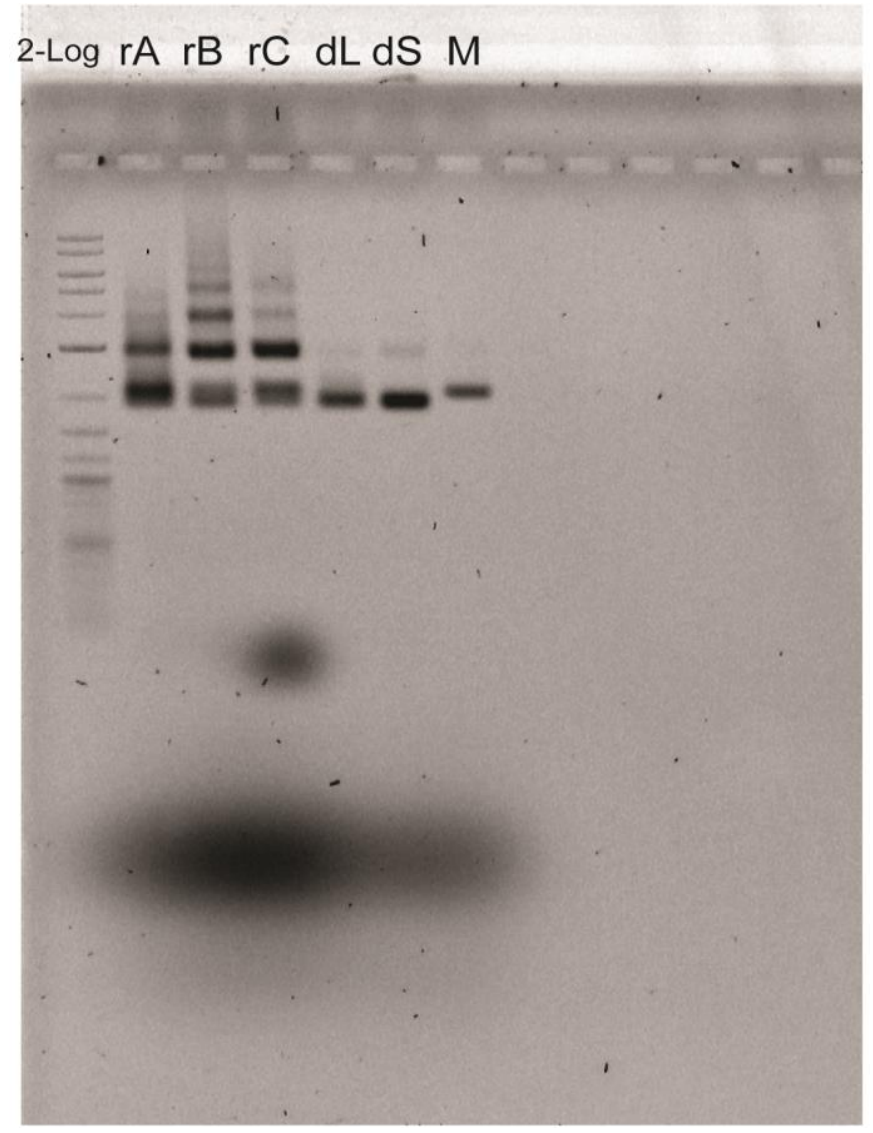

Figure S3. The full image of agarose gel featured in Figure $2 \mathrm{a}$. Gel was stained with $0.5 \mu \mathrm{g} / \mathrm{mL}$ ethidium bromide after running for 3 hours at 60V. Left lane: 2-Log DNA ladder (New England Biolabs). The wide dense band at the bottom is bromophenol blue used in the loading buffer.

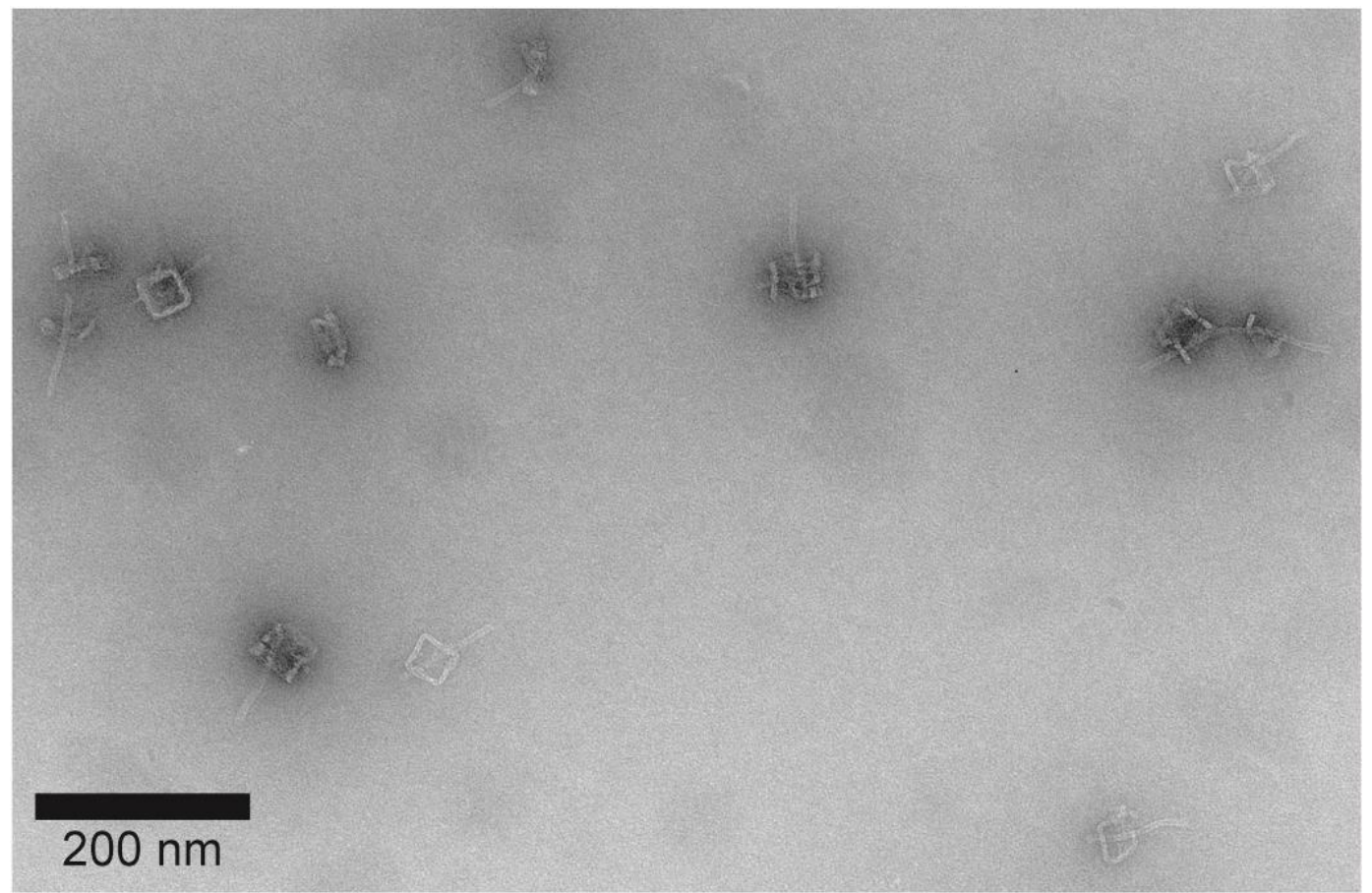

Figure S4-1. Unmarked TEM image of rA as featured in Figure 2b. 


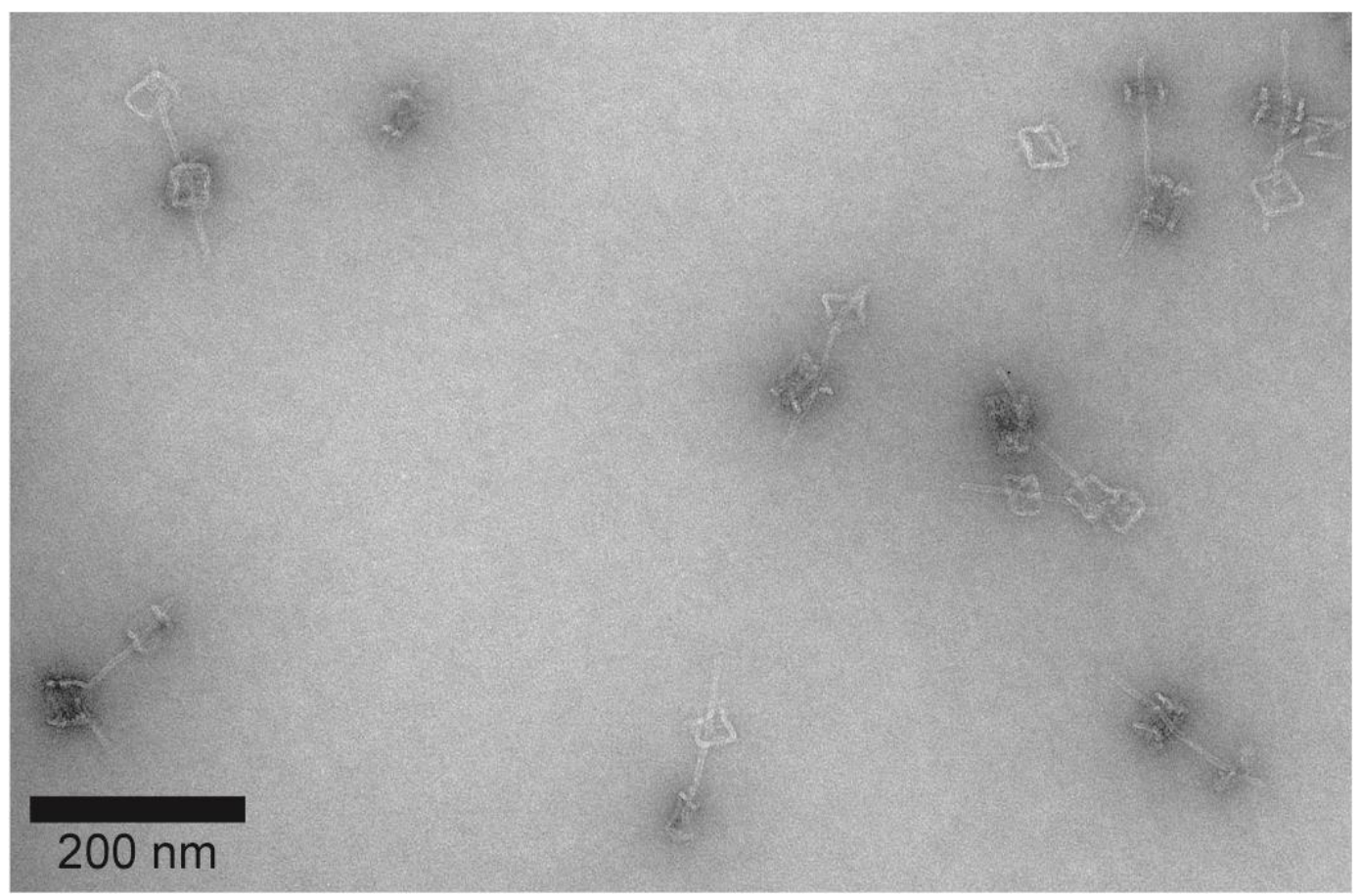

Figure S4-2. Unmarked TEM image of rB as featured in Figure $2 b$.

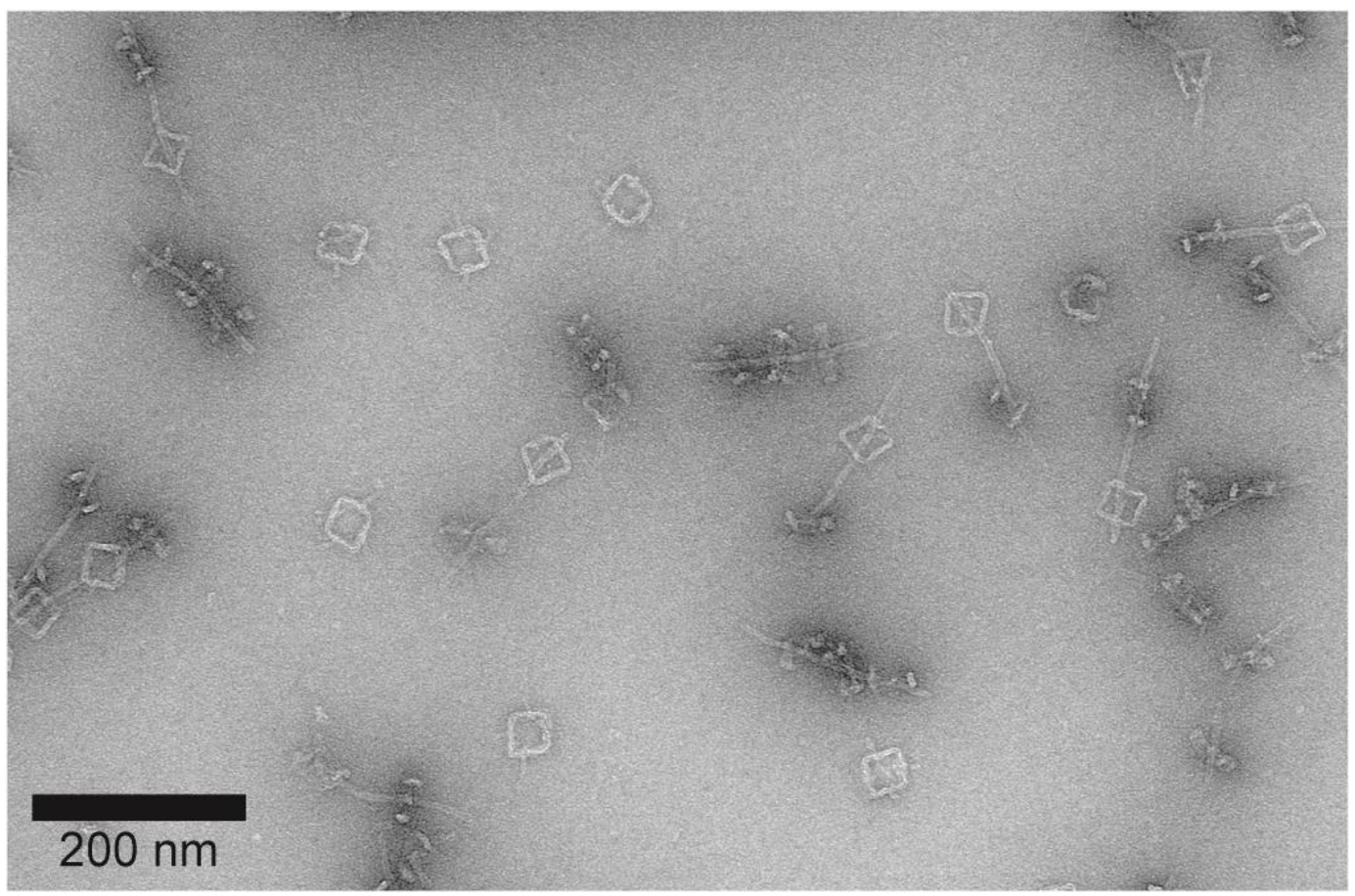

Figure S4-3. Unmarked TEM image of $\mathrm{rC}$ as featured in Figure $2 \mathrm{~b}$. 


\section{Fresh mix ( $r C)$}
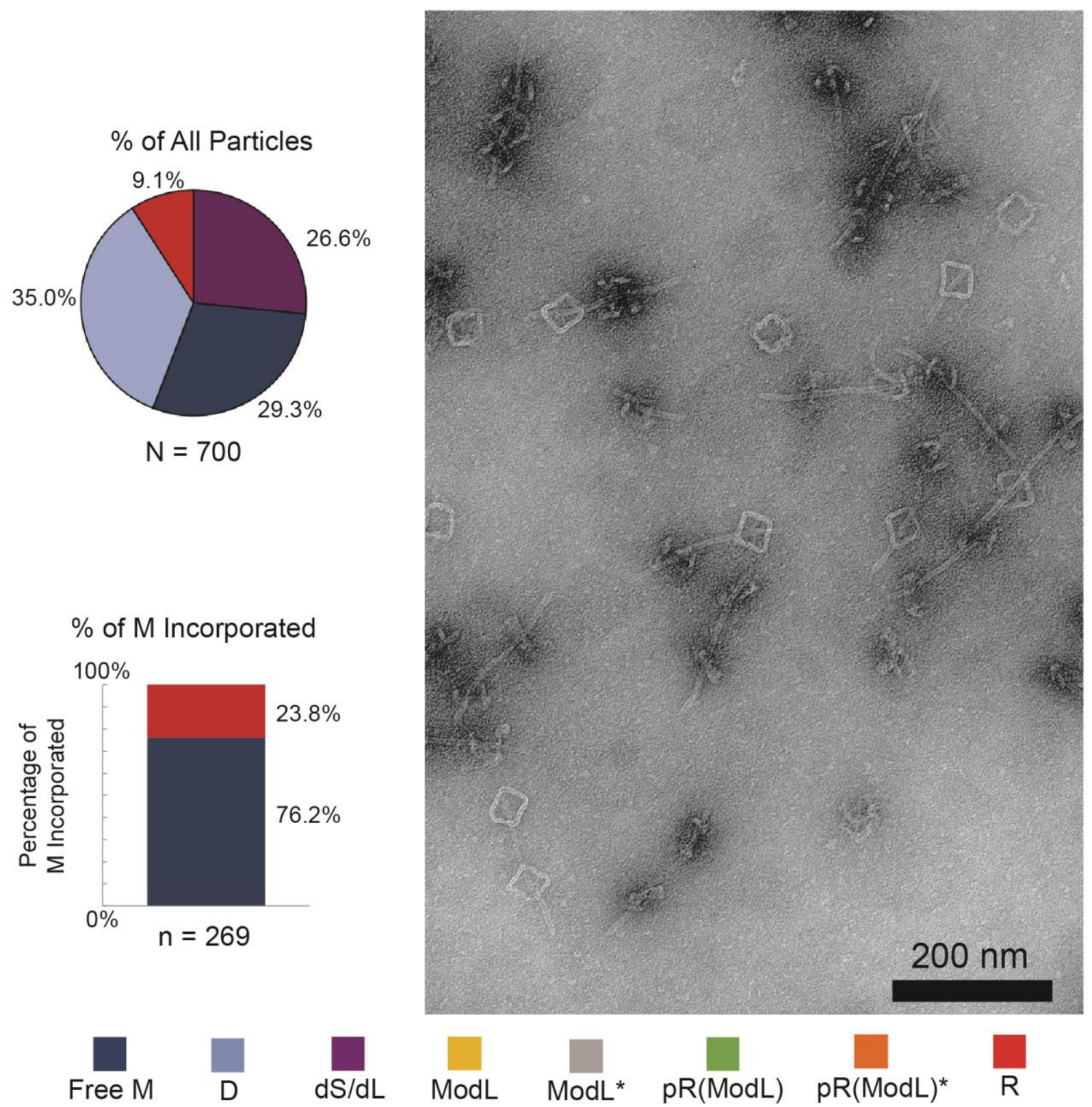

Figure S5-1. Testing rotaxane thermal stability over time: As the starting point for these experiments, a fresh $\mathrm{rC}$ mix was prepared according to the same protocol as used for $\mathrm{rC}$ in Figure 2. The measured $M$ incorporation rate in fresh $\mathrm{rC}(\sim 24 \%)$ is similar to the value of Figure 2 $(17 \%)$; the small difference reflects the experimental and counting errors in two independent preparations. 


\section{rC mix after heating at $44^{\circ} \mathrm{C}$ for $20 \mathrm{~h}$}
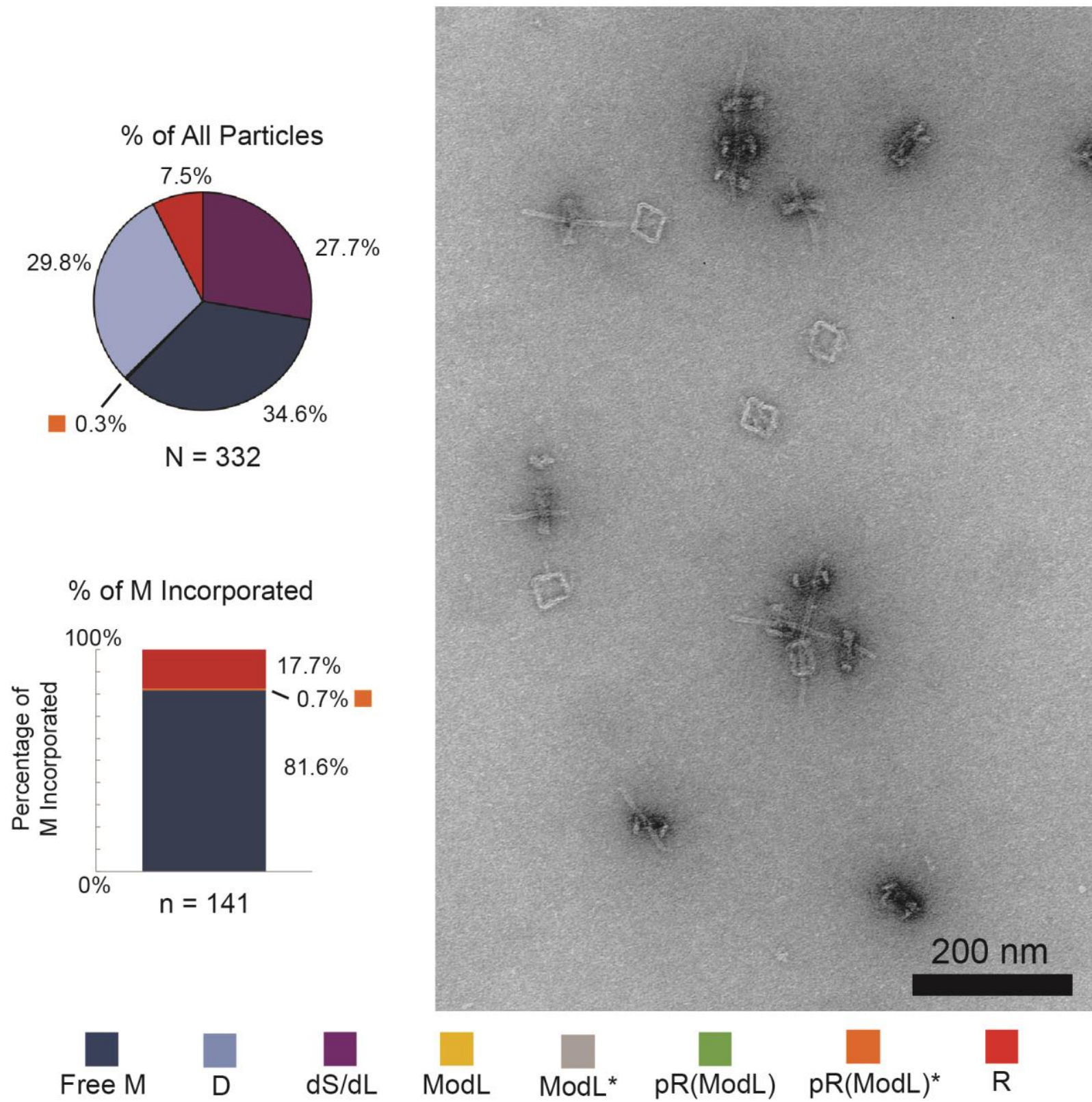

Figure S5-2. Testing rotaxane thermal stability over time: A $44{ }^{\circ} \mathrm{C}, 20$ hour incubation of $\mathrm{rC}$ mix showed similar total percentage of rotaxanes and percentage incorporation of $\mathrm{M}$ compared to the fresh rC mix (Figure S5-1). 


\section{rC mix after room temperature incubation for 36 days}
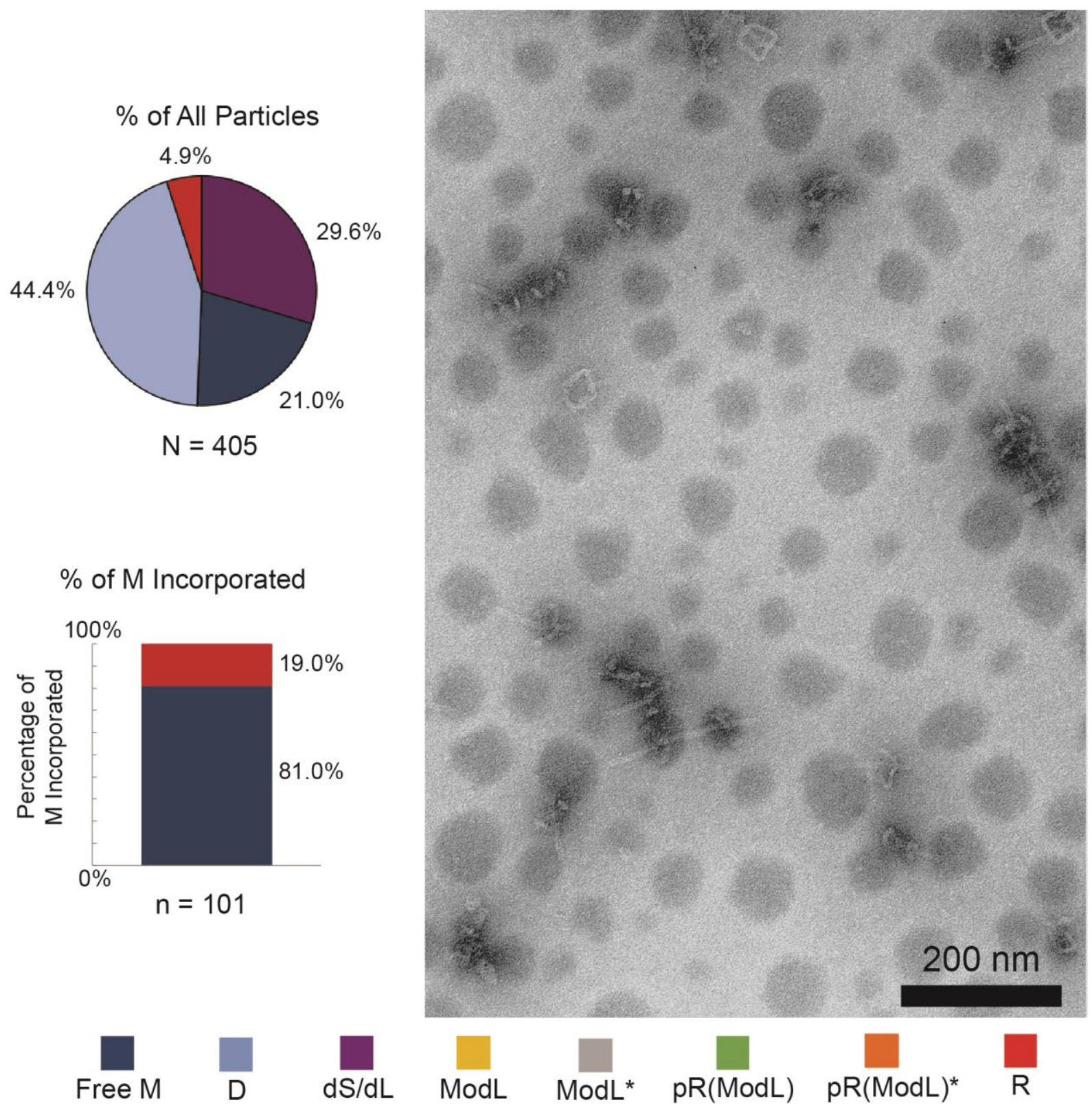

Figure S5-3. Testing rotaxane thermal stability over time: A protracted room temperature postassembly incubation of $\mathrm{rC}$ mix showed similar total percentage of rotaxanes and percentage incorporation of $\mathrm{M}$ compared to the fresh $\mathrm{rC}$ mix (Figure S5-1). 


\section{Unambiguous ModL}

1)
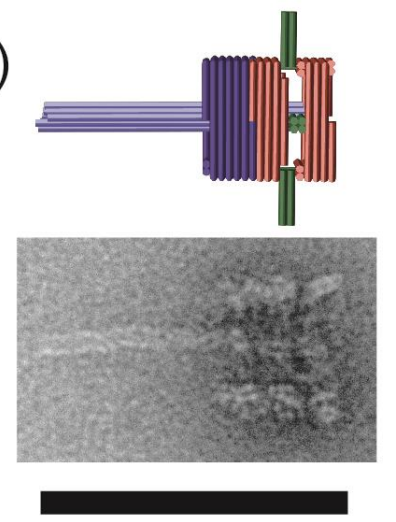

$\underline{\text { Ambiguous ModL* }}$

$100 \mathrm{~nm}$

2)
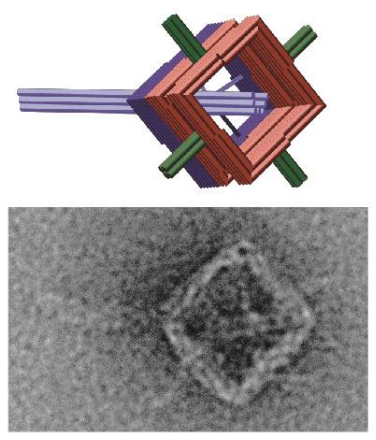

$100 \mathrm{~nm}$

\section{Unambiguous ModL*}

3)
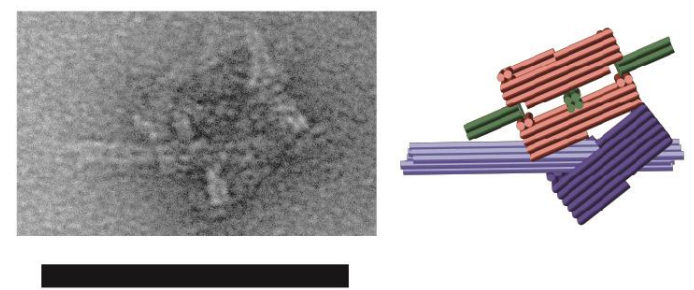

$100 \mathrm{~nm}$

Figure S6-1. Cartoon models and example TEM images demonstrating the visual appearance of threading used to categorize ModL and ModL*. Unambiguous ModL clearly showed the dumbbell axle passing through the M-docked stopper as in (1). Ambiguous ModL* nanostructure as in (2), which was classified as ModL* in all cases, showed a flattened M-docked stopper with unclear threaded or dethreaded topology. Our choice to classify such ambiguous structures as ModL* might have caused underestimation of intermediates within rA capable of producing $\mathrm{pR}(\mathrm{ModL})$ and eventually R. Finally, the M-docked stopper of unambiguous $\mathrm{pR}(\mathrm{ModL}) *$ nanostructure as shown in (3) was clearly not threaded through the axle and as such could likely not produce $\mathrm{pR}(\mathrm{ModL})$ or rotaxane. Other characterization methods such as cryo-electron tomography may help with the structural determination of intermediates in the future. 


\section{Unambiguous $\mathrm{pR}(\mathrm{ModL})$}

1)

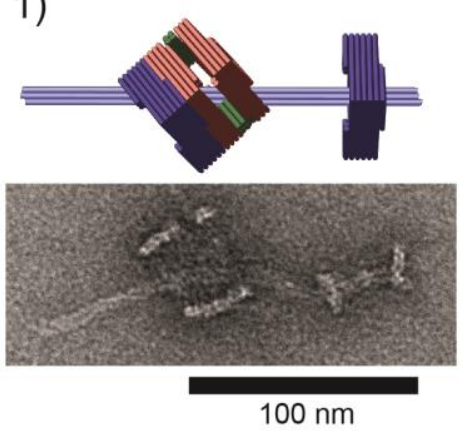

Ambiguous $\mathrm{pR}(\mathrm{ModL})^{*}$

2)
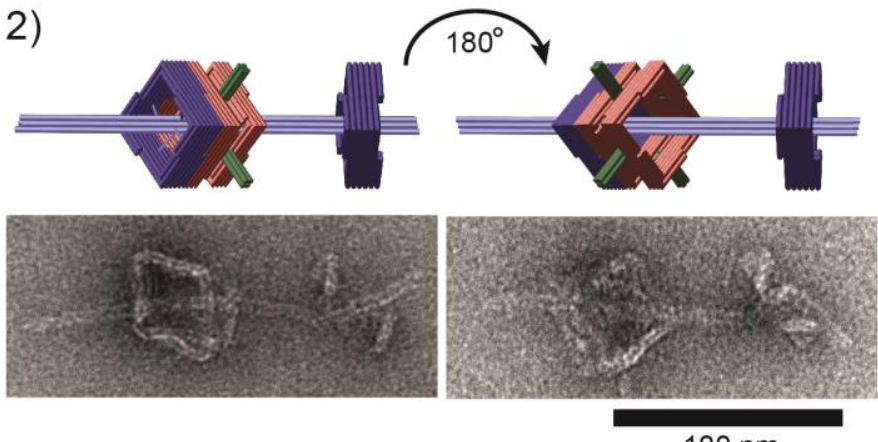

$100 \mathrm{~nm}$

\section{Unambiguous $\mathrm{pR}(\mathrm{ModL})^{*}$ Variants}

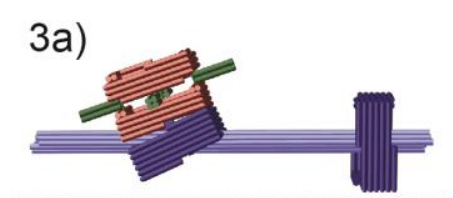

3b)
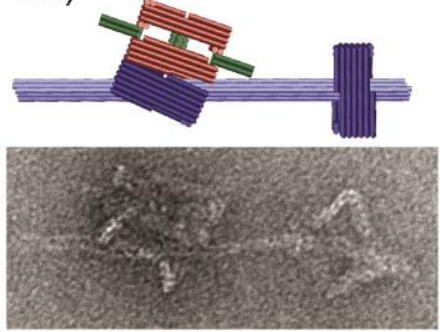

3c)
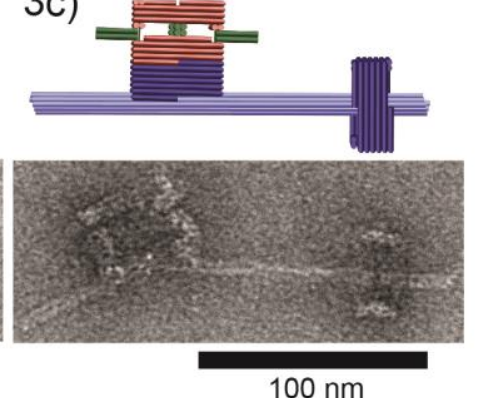

Figure S6-2. Cartoon models and example TEM images demonstrating the visual appearance of threading used to categorize $\mathrm{pR}(\mathrm{ModL})$ and $\mathrm{pR}(\mathrm{ModL}) *$. Unambiguous $\mathrm{pR}(\mathrm{ModL})$ clearly showed the dumbbell axle passing through the M-docked stopper as in (1). Ambiguous $\mathrm{pR}(\mathrm{ModL}) *$ nanostructure as in (2), which was classified as $\mathrm{pR}(\mathrm{ModL}) *$ in all cases, showed a flattened M-docked stopper with unclear threaded or dethreaded topology. The cartoon model depicts the likely topology of an ambiguous $\mathrm{pR}(\mathrm{ModL}) *$ if it in fact contains fully threaded docked stopper. Our choice to classify such ambiguous structures as $\mathrm{pR}(\operatorname{ModL}) *$ might have caused underestimation of the total intermediates in $\mathrm{rB}$ capable of producing $\mathrm{R}$ upon $\mathrm{M}$ release. Finally, the M-docked stopper of unambiguous pR(ModL)* nanostructure as shown in (3a-c) was clearly not threaded through the axle and as such could not produce rotaxane. Each variant of (3) is distinguishable according to the orientation of the docked stopper relative to the axle. 


\section{$\mathrm{dL}+\mathrm{dS}$}

\section{$\%$ of All Particles}
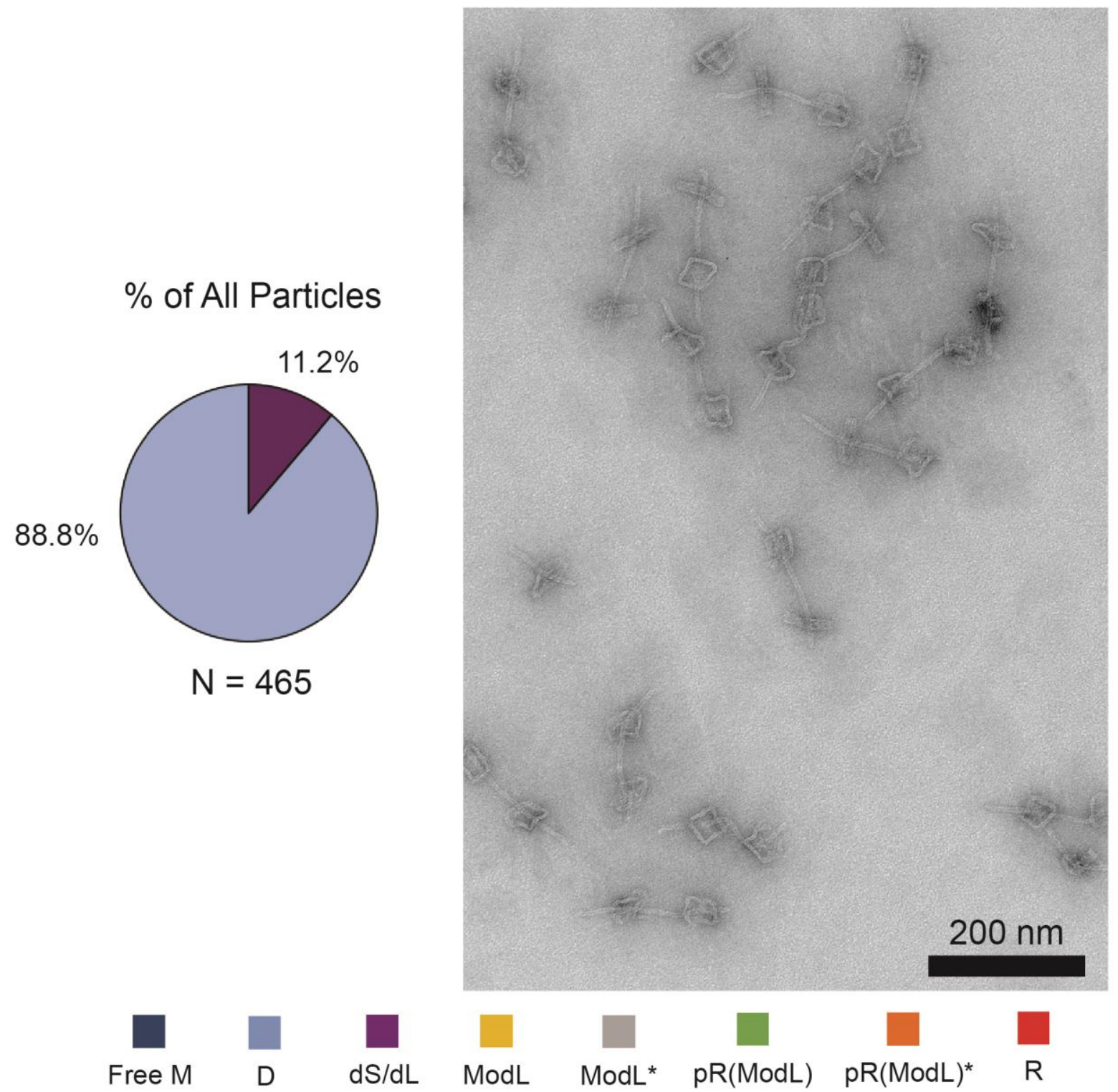

Figure S7-1. The first step in an attempted disordered assembly of rotaxane: Dimerization of dL and dS. Note that the half-dumbbells dimerized efficiently; very few half-dumbbells remained as monomers. 


\section{$\mathrm{dL}+\mathrm{dS}+\mathrm{M}+\mathrm{X}$ linking strands}

\section{$\%$ of All Particles}

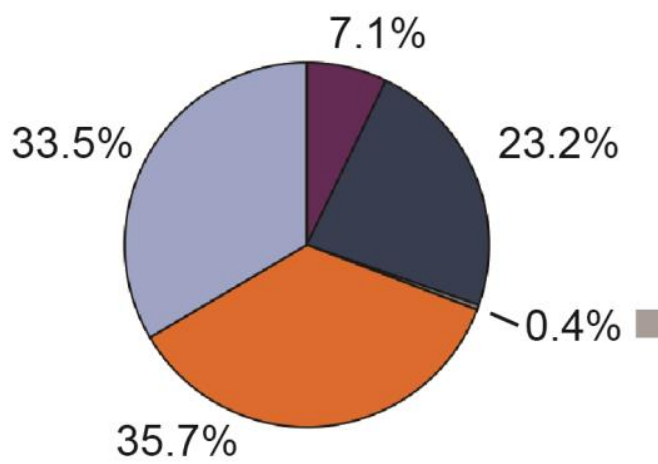

$$
\mathrm{N}=224
$$

$\%$ of M Incorporated

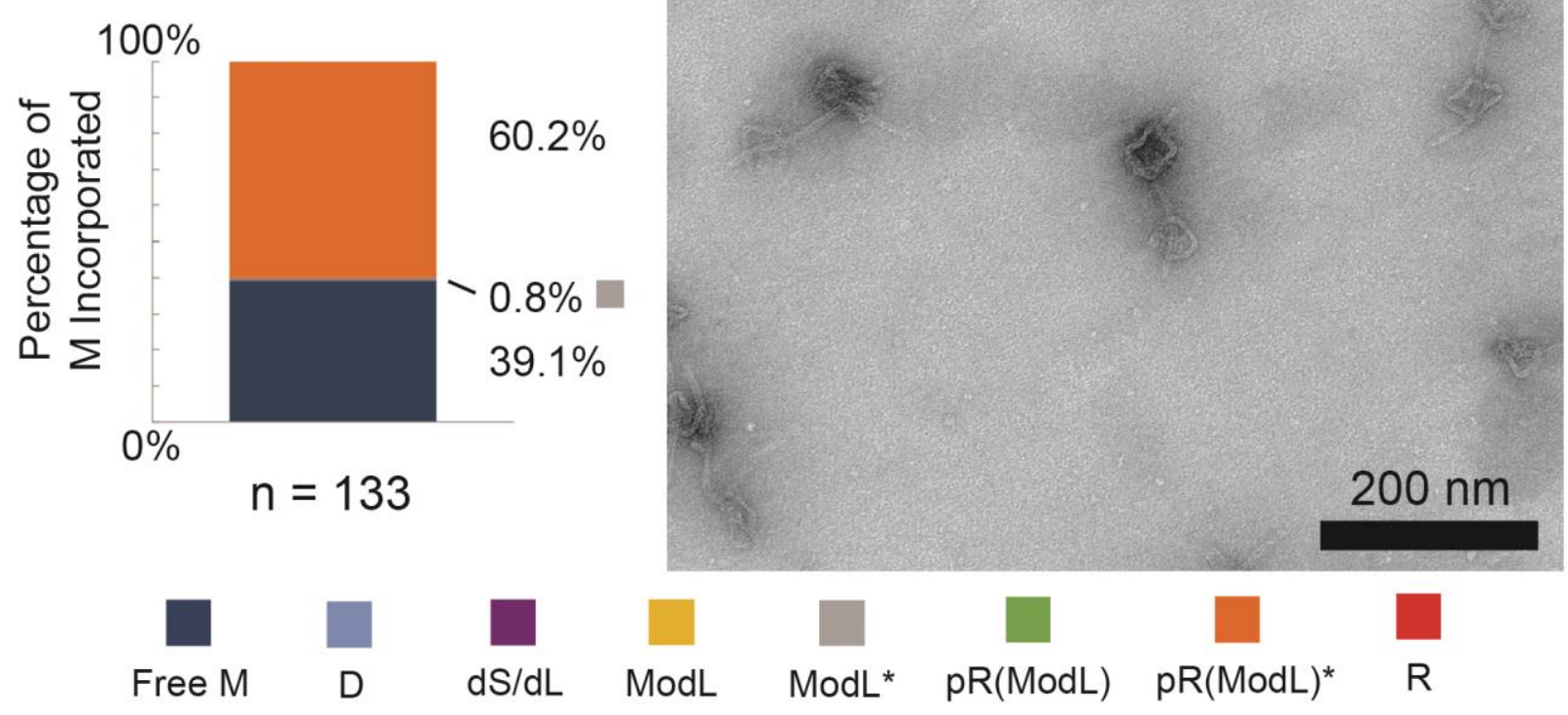

Figure S7-2. The second step in an attempted disordered assembly of rotaxane: Monomeric M and $\mathrm{X}$ linking strands were added to the reaction mix shown in Figure S7-1, causing docking of $\mathrm{M}$ to $\mathrm{D}$ and producing only malformed intermediates catalogued as $\mathrm{pR}(\mathrm{ModL})^{*}$. Due to steric hindrance by the stoppers of the preformed dumbbell $\mathrm{D}$, threading of $\mathrm{M}$ after formation of $\mathrm{D}$ was impossible. 


\section{$\mathrm{dL}+\mathrm{dS}+\mathrm{M}+\mathrm{X}$ linking strands $+\mathrm{X}^{\prime}$ displacing strands}

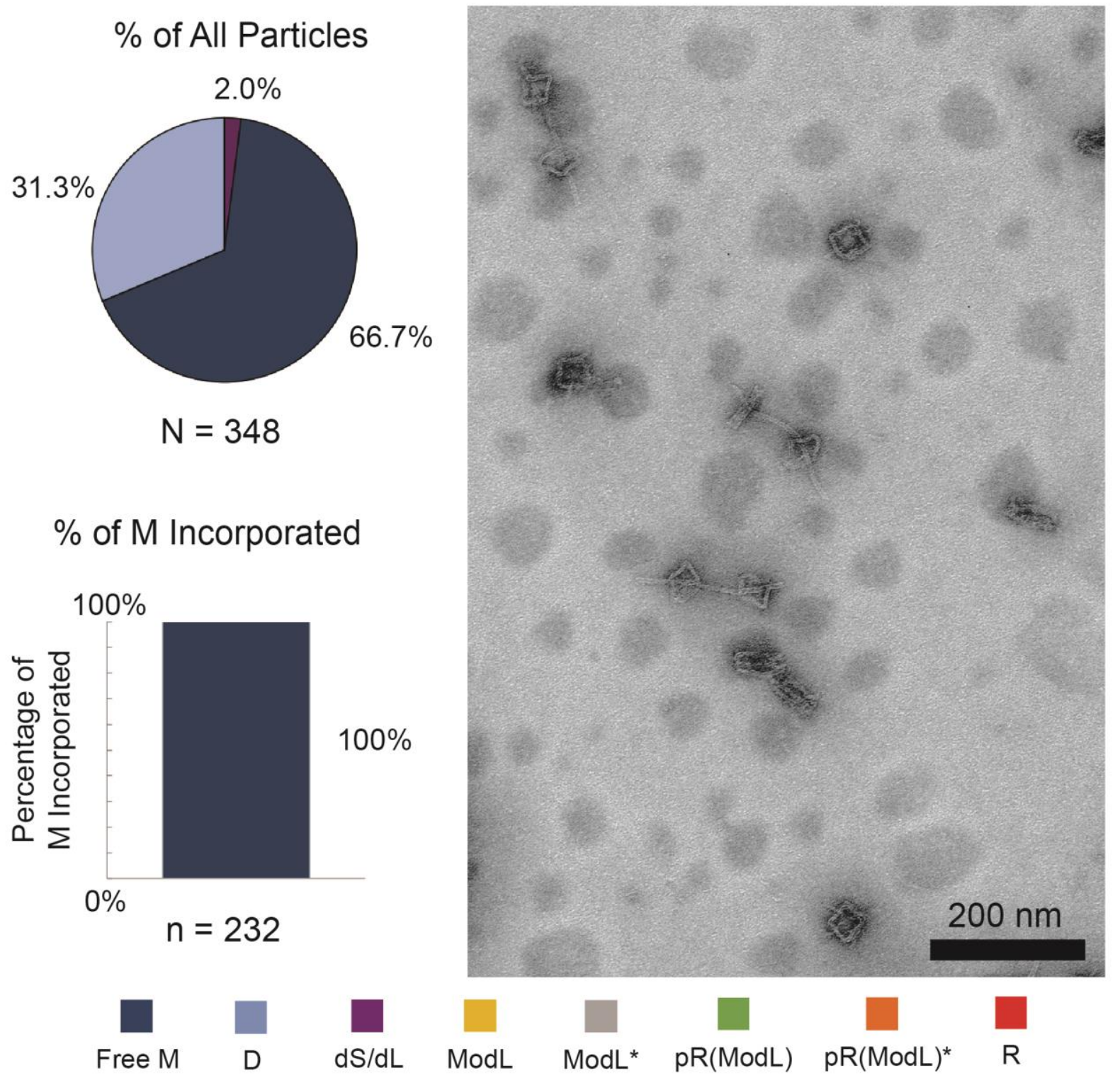

Figure S7-3. The final step in an attempted disordered assembly of rotaxane: Addition of 5-fold excess of $\mathrm{X}^{\prime}$ displacing strands (relative to the $\mathrm{X}$ linking strands) to the reaction mix shown in Figure S7-2 resulted in release of $\mathrm{M}$ from $\mathrm{pR}(\mathrm{ModL}) *$. Note that strand displacement-mediated release of $\mathrm{M}$ yielded no rotaxane detectable by TEM. 


\section{$M+d S+Y$ linking strands}

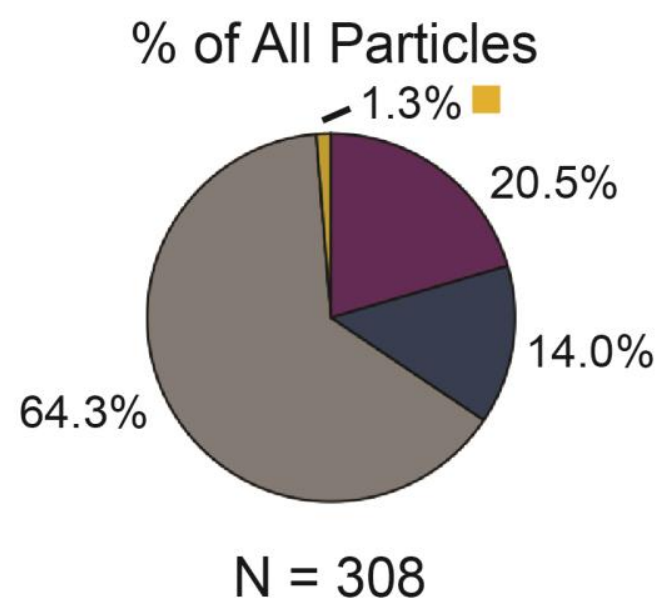

$\%$ of $\mathrm{M}$ Incorporated
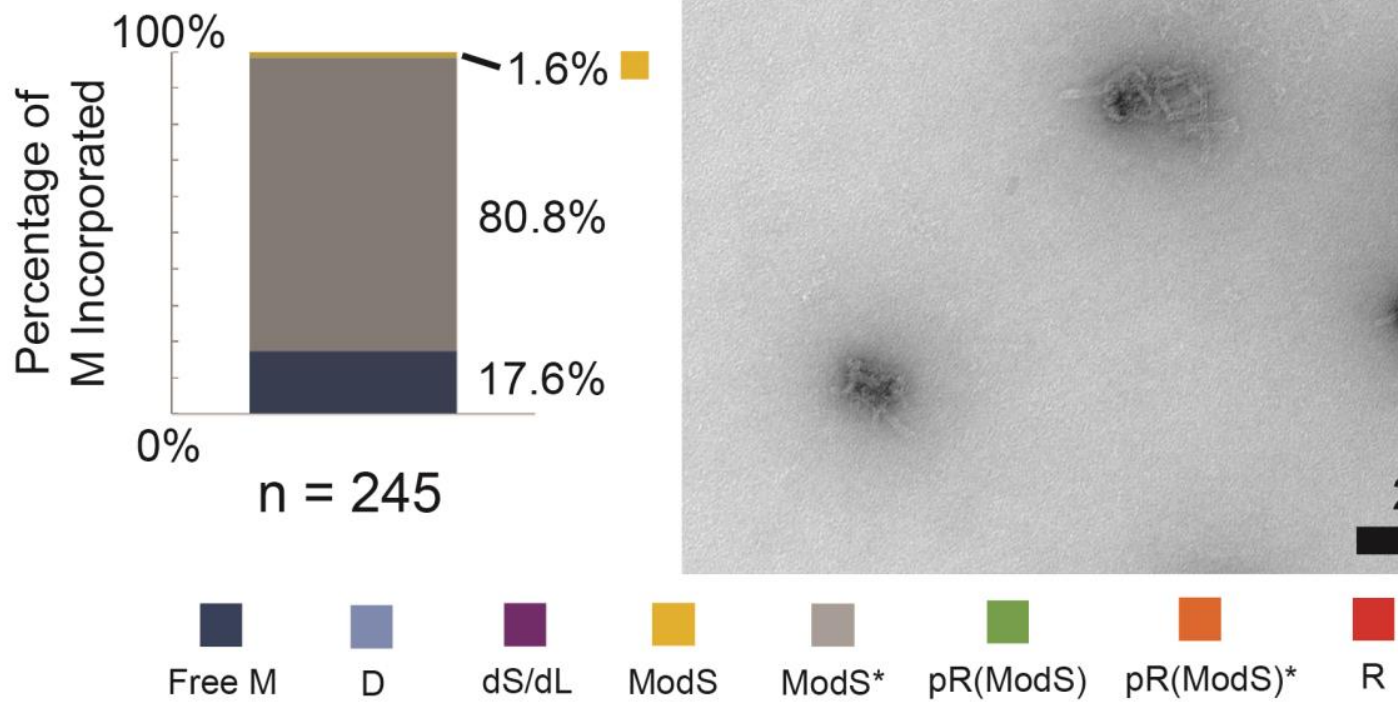

Figure S8-1. Assembly of rotaxanes by first threading $M$ through the long-axle of dS (i.e., $M+$ $\mathrm{dS}+\mathrm{Y}$ linking strands, cf. top). Few rotaxanes were produced at the end (Figure S8-3). Moreover, all pseudo-rotaxane intermediates (Figure S8-2) appeared as the malformed version $\mathrm{pR}(\mathrm{ModS})^{*}$, suggesting that $\mathrm{M}$ threading over the long axle segment of $\mathrm{dS}$ is less favorable than $M$ threading over the short axle segment of $\mathrm{dL}$, resulting in the disparity in R assembly efficiency. 


\section{$M+d S+Y$ linking strands $+d L$}

\section{$\%$ of All Particles}

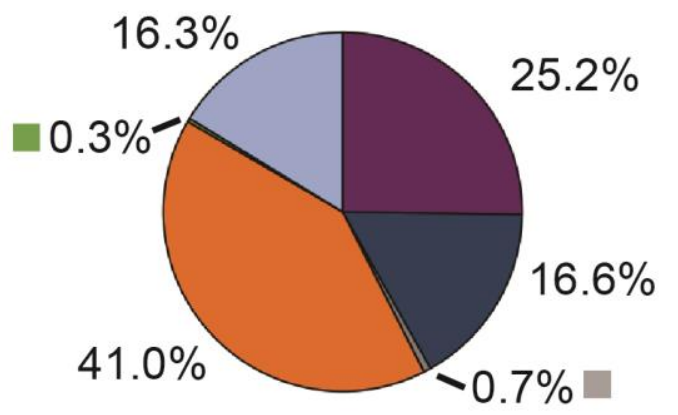

$$
\mathrm{N}=301
$$

\section{$\%$ of M Incorporated}
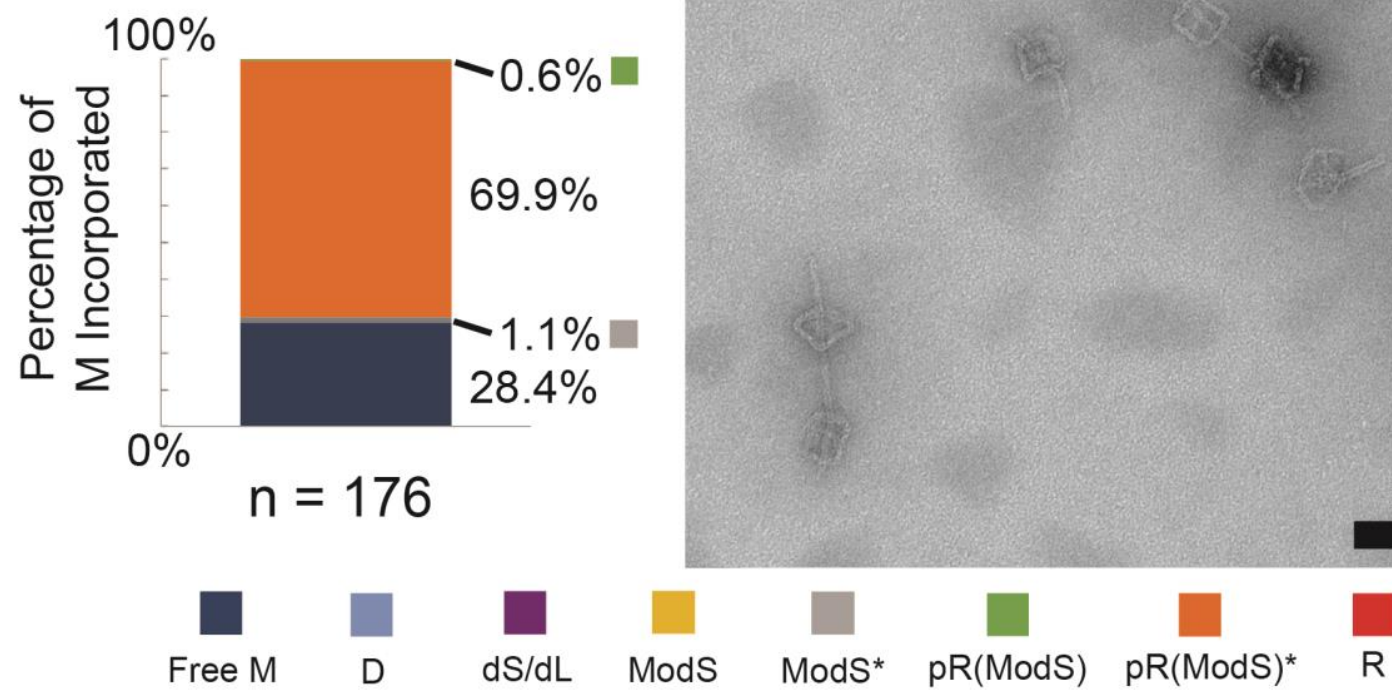

Figure S8-2. The second stage in assembling rotaxanes via long-axle threading. All pseudorotaxane intermediates were classified as malformed pseudorotaxanes according to the criteria described in S6-2. 


\section{$M+d S+Y$ linking strands $+d L+Y^{\prime}$ displacing strands}

\section{$\%$ of All Particles}

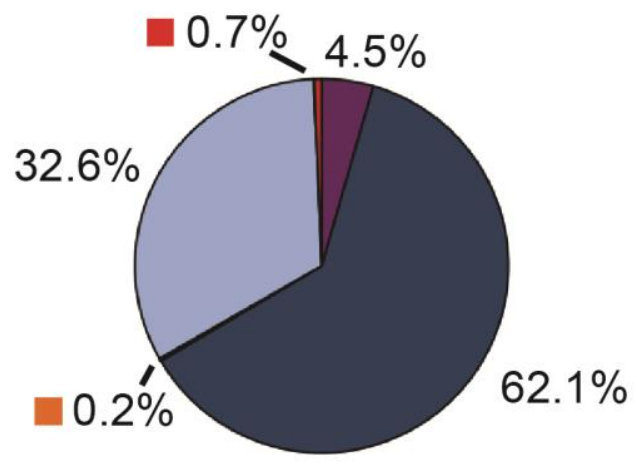

$N=448$

$\%$ of $\mathrm{M}$ Incorporated
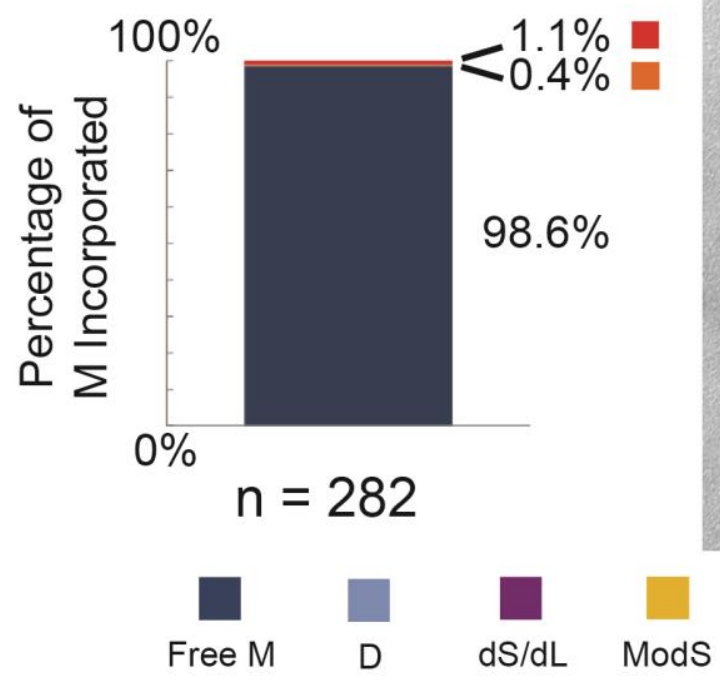
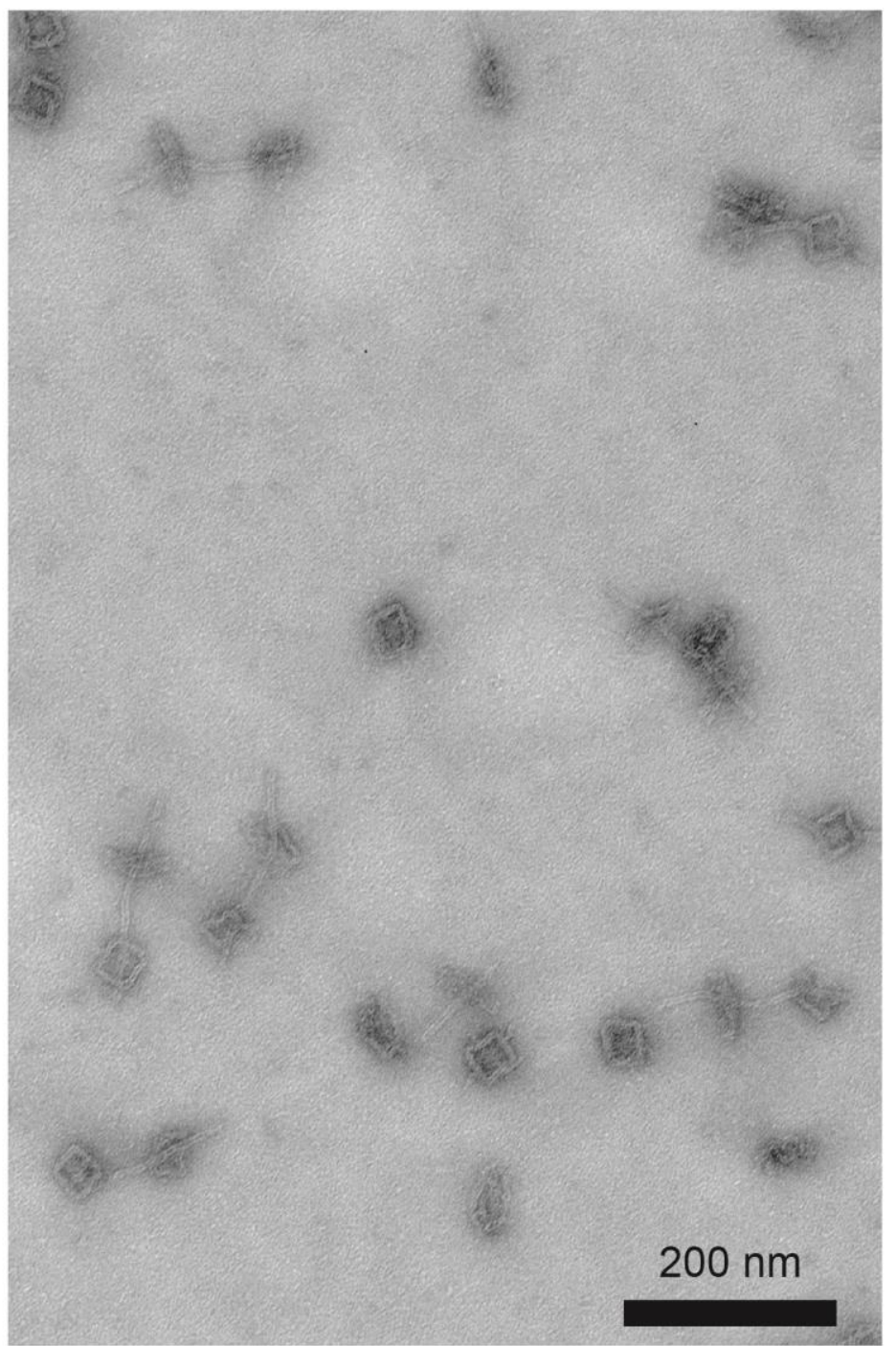

ModS $^{*} \quad \mathrm{pR}($ ModS $) \quad \mathrm{pR}(\operatorname{ModS})^{*} \quad \mathrm{R}$

Figure S8-3. The final M release stage of rotaxane assembly via long-axle threading. $\mathrm{R}$ assembly efficiency of this approach is pronouncedly less than that of the short-axle threading approach shown in Figure 2. 


\section{dL Docking}
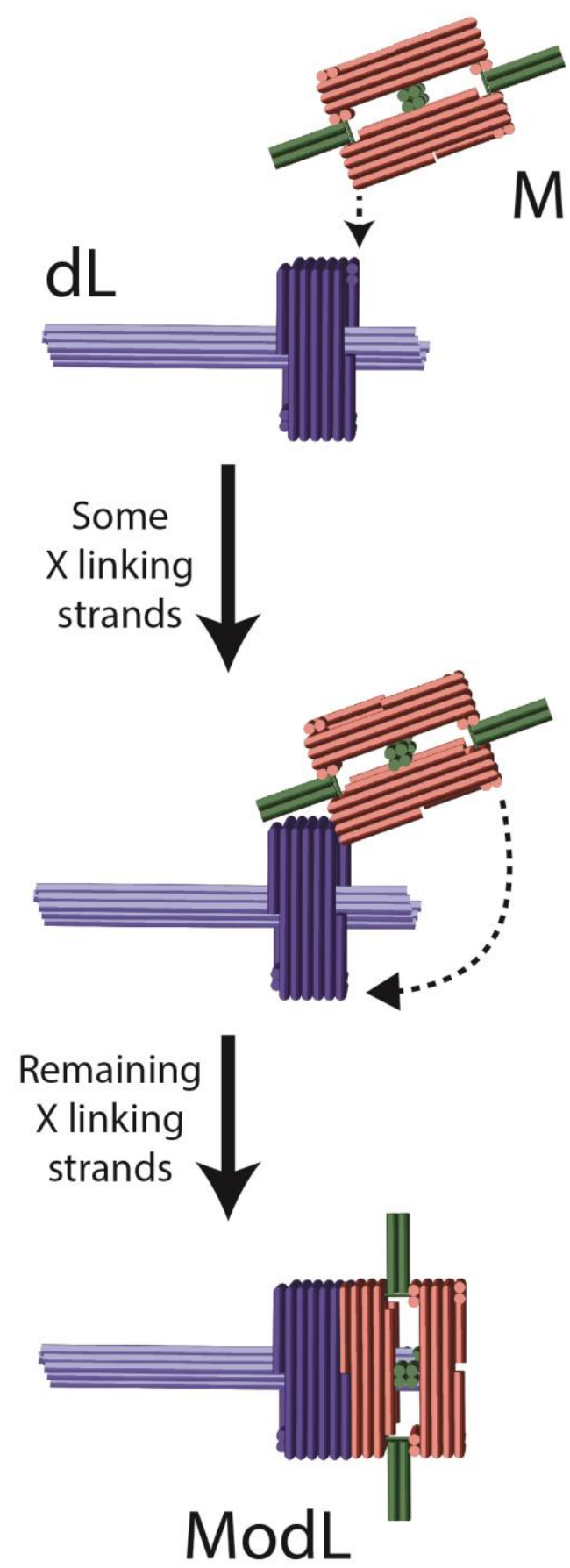
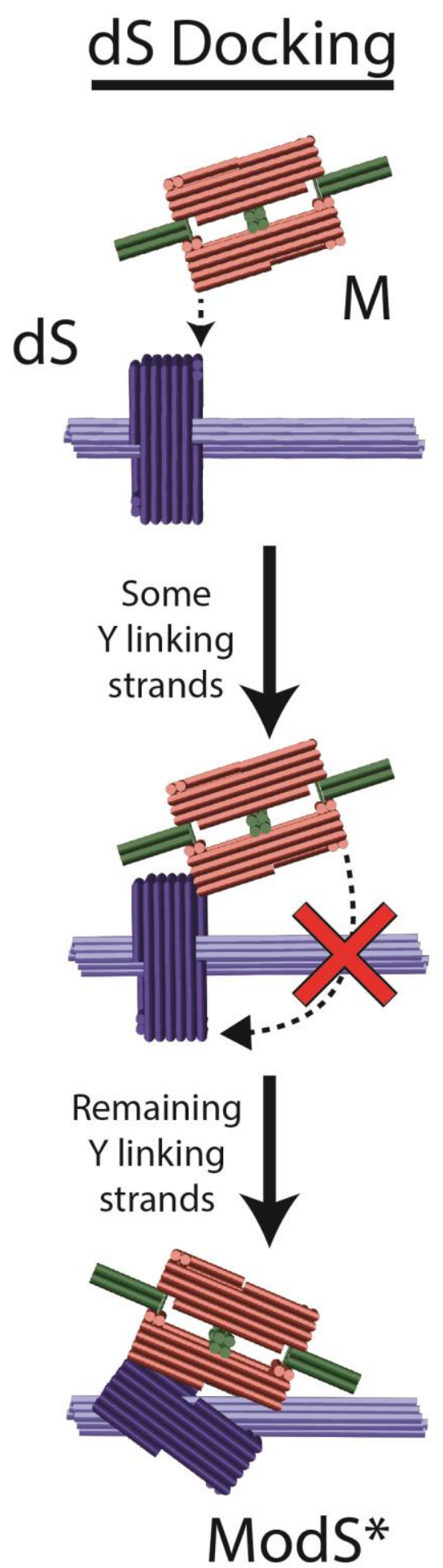

Figure S9-1. Illustration of the hypothetical mechanism of $M$ threading over the short or long axle end of a half-dumbbell. The docking surface of $\mathrm{M}$ can clear and thus incrementally thread over the short axle segment (left). However, M cannot clear and thread the long axle segment (right), leading to formation of ModS*, which likely cannot yield R upon addition of $\mathrm{dL}$ and displacing strands (for practical demonstration, compare the results of Figure 2 and Figure S8). 


\section{Stopper Flexibility and Reduced Yield}

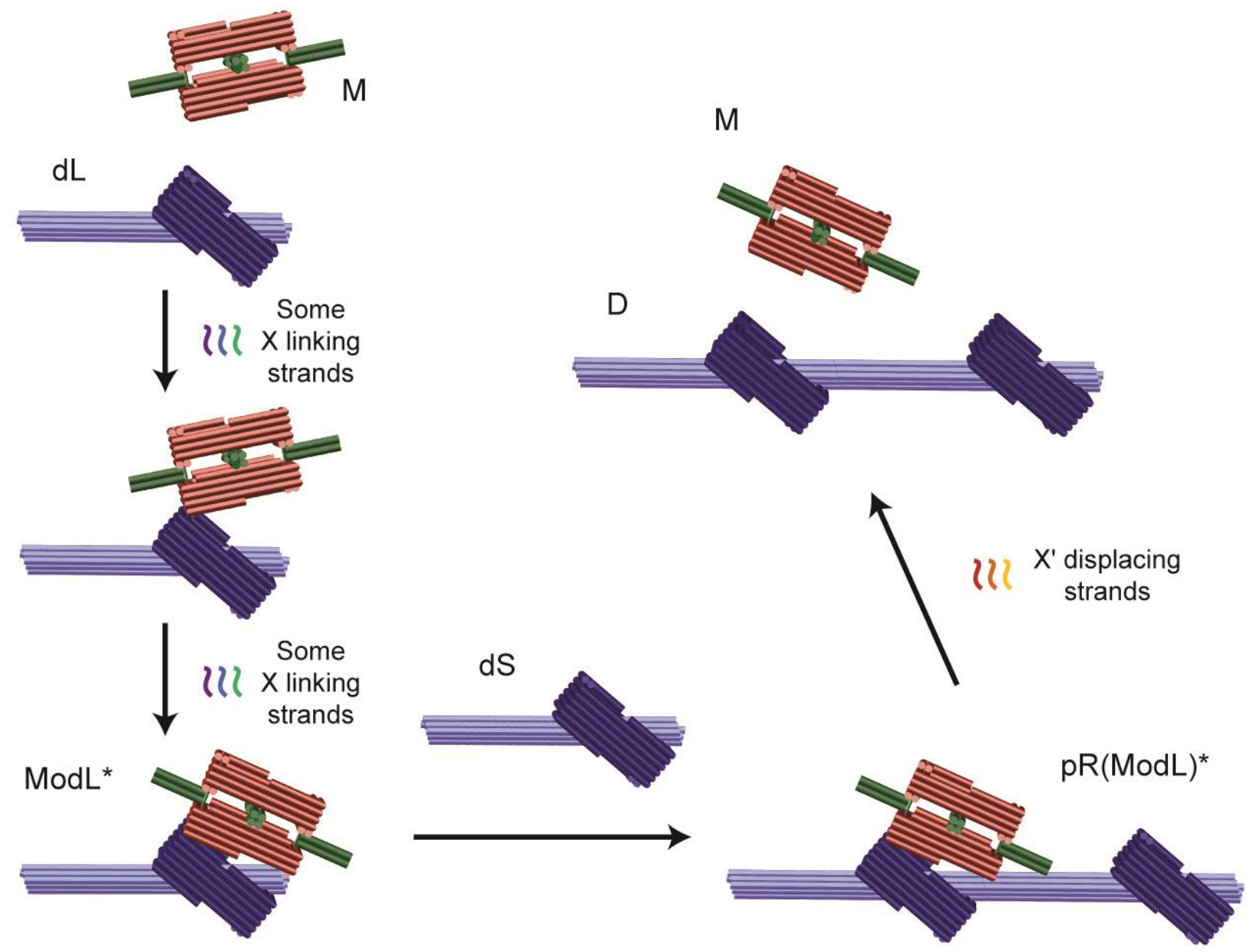

Figure S9-2. Reduced assembly efficiency may occur due to the tilting flexibility of the stopper. Here, even though the stopper is on the short end of the axle, the full engagement of macrocycle may be blocked, yielding the misassembled intermediate $\mathrm{pR}(\mathrm{ModL})^{*}$. 


\section{Linker-free rotaxane assembly $(\mathrm{M}+\mathrm{dL}+\mathrm{dS})$}

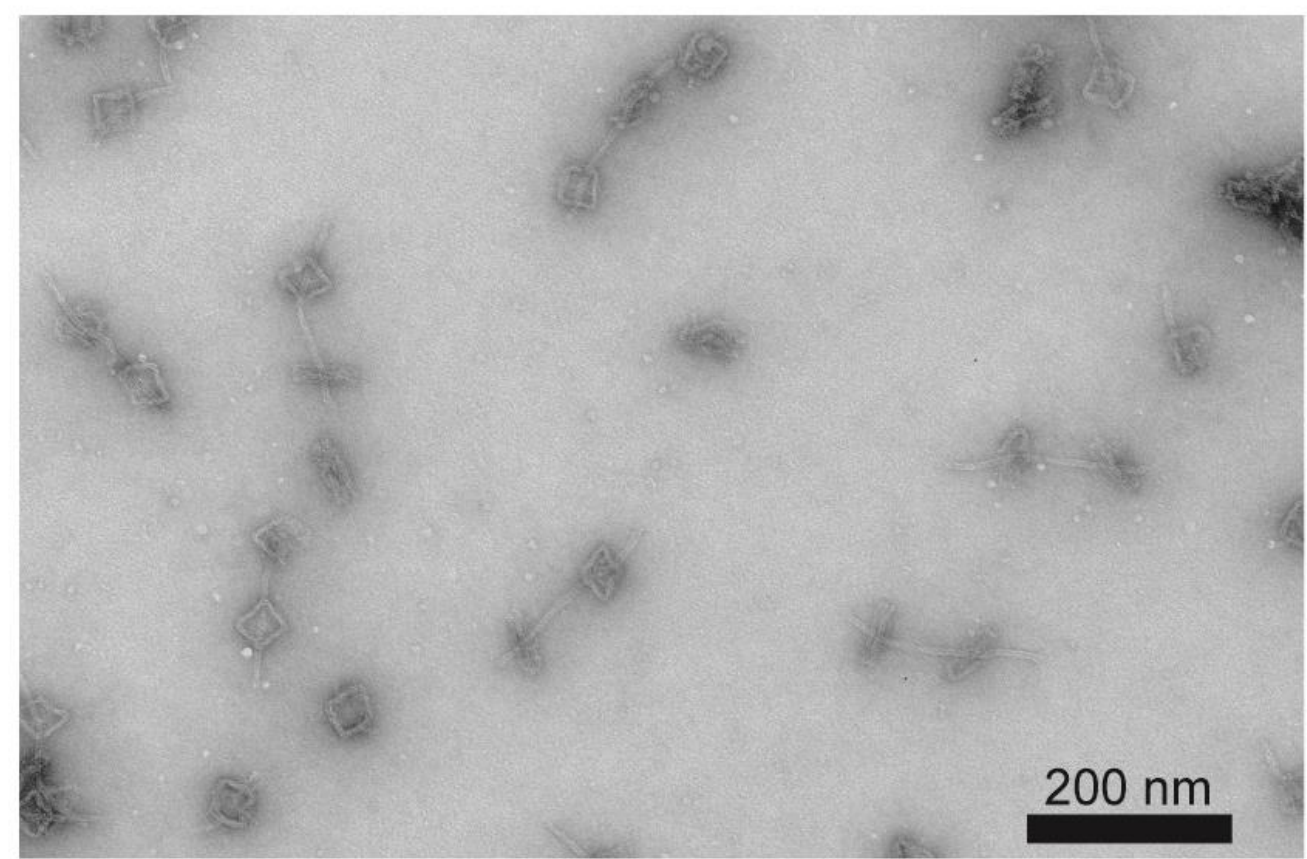

\section{$\%$ of All Particles}

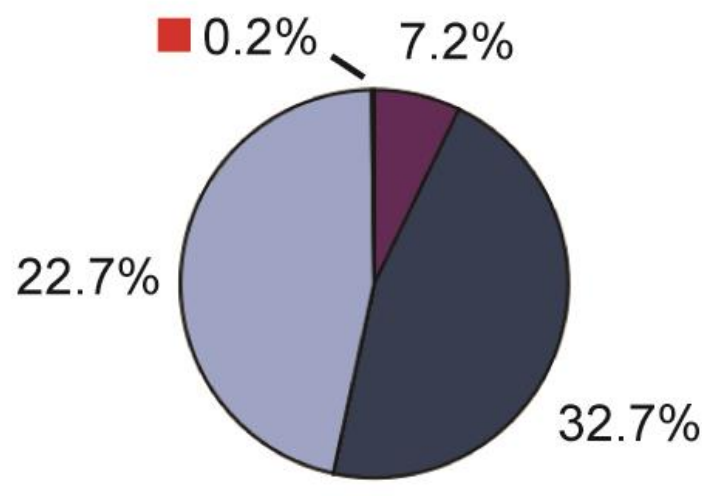

$\mathrm{N}=500$
$\%$ of $\mathrm{M}$ Incorporated
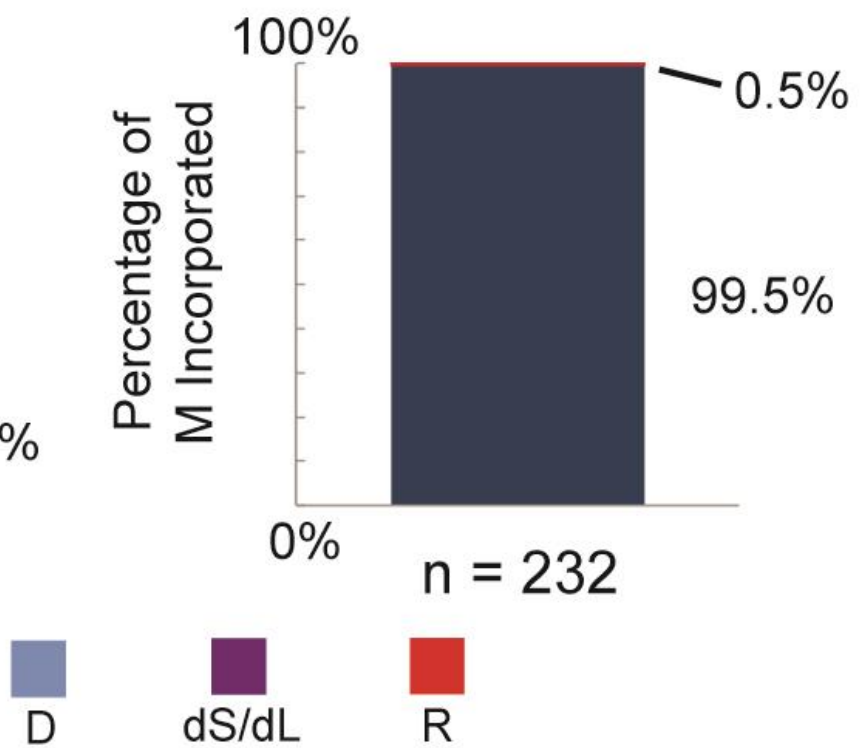

Figure S10. Linker-free assembly of rotaxane. The three monomers dL, dS, and M were incubated simultaneously at $40{ }^{\circ} \mathrm{C}$ for 16 hours in the absence of auxiliary linking strands. Few rotaxanes form as a result of random threading, suggesting the critical contribution of the linking strategy to the rotaxane assembly efficiency. 


\section{M position maxima and minima}
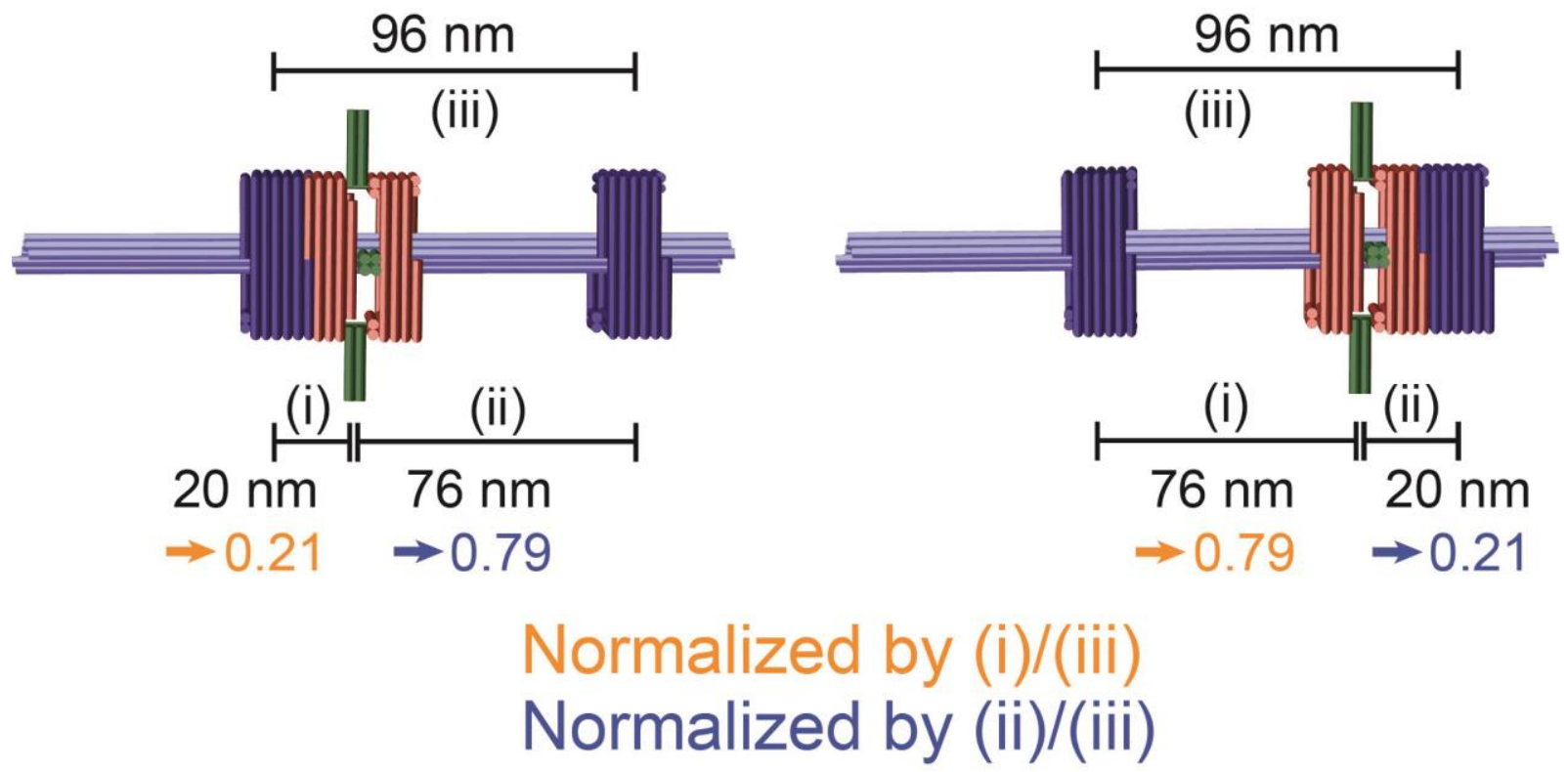

Full movement range: $0.21-0.79$

Figure S11. Design dimensions and corresponding normalized values of maximum and minimum macrocycle position relative to either dumbbell stopper. According to our design, the minimum center-to-center distance between the macrocycle and stopper is $20 \mathrm{~nm}$. Thus, the upper and lower limits of macrocycle position when normalized to the stopper-to-stopper distance (center-to-center: $96 \mathrm{~nm}$ ) are 0.79 and 0.21 , respectively. These limits are experimentally corroborated by our observation that very few macrocycles are measured at points beyond either of these extremes (Figure 3a). 


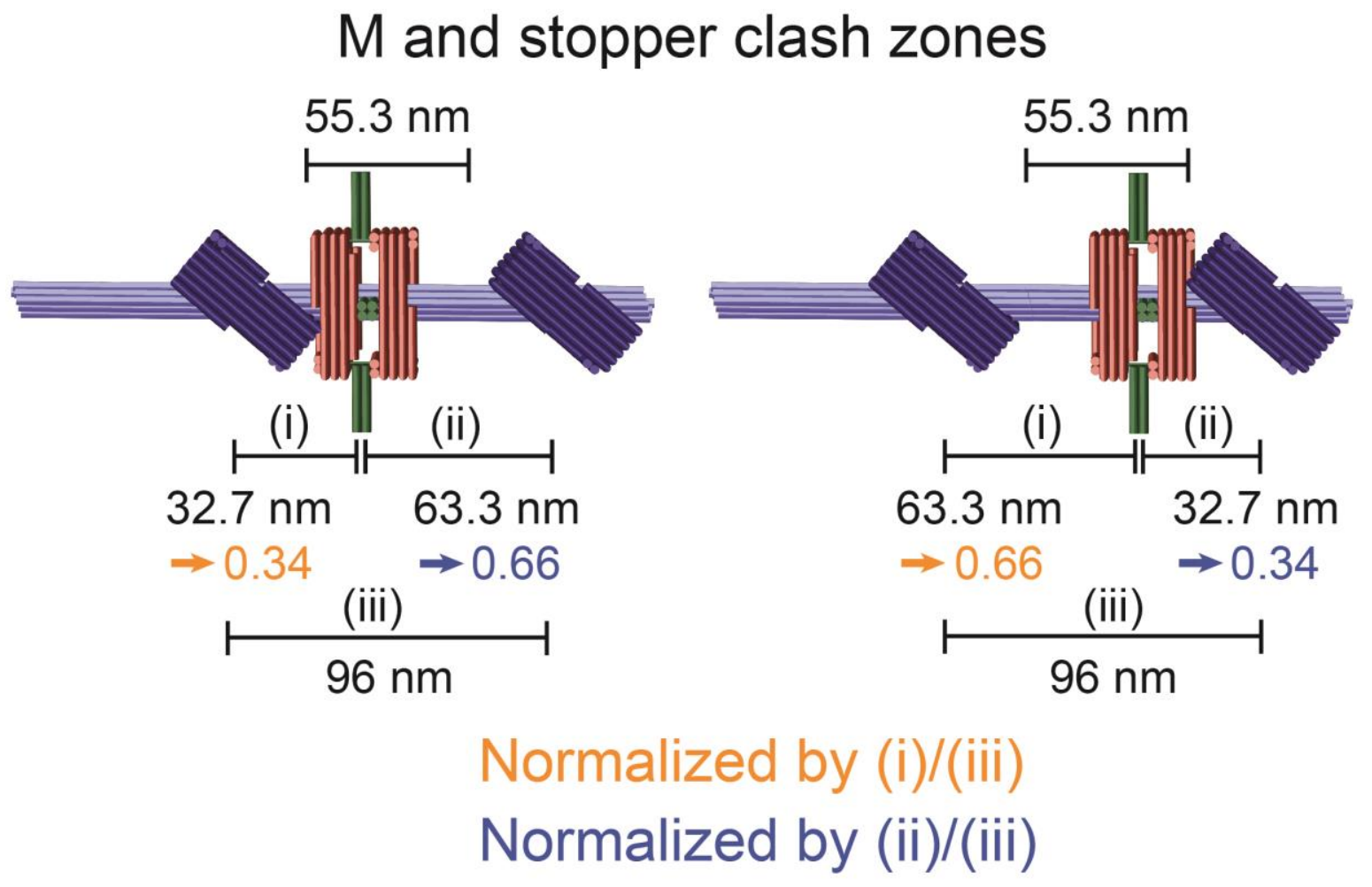

Unhindered zone: $0.34-0.66$

Clash zones: $0.21-0.34,0.66-0.79$

Figure S12. Cartoon models explaining "clash zones" caused by wobbly nature of our dumbbell's stoppers. Either stopper can theoretically impinge on a distance of $32.7 \mathrm{~nm}$ or a normalized value of 0.34 . These terminal clash zones are likely responsible for the steep decline in macrocycle presence past 0.34 and 0.66 relative to either stopper (Figure $3 \mathrm{a}$ ). 


\section{$\mathrm{pR}(\operatorname{ModS})$}
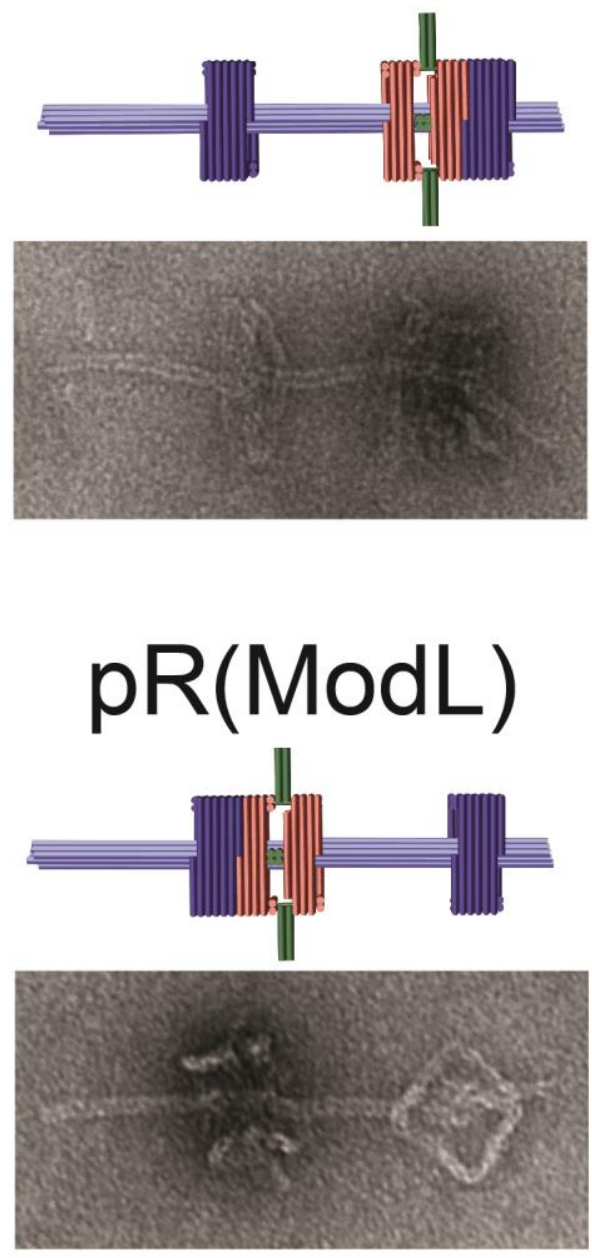

100 nm
$\mathrm{pR}(\operatorname{ModS})^{*}$
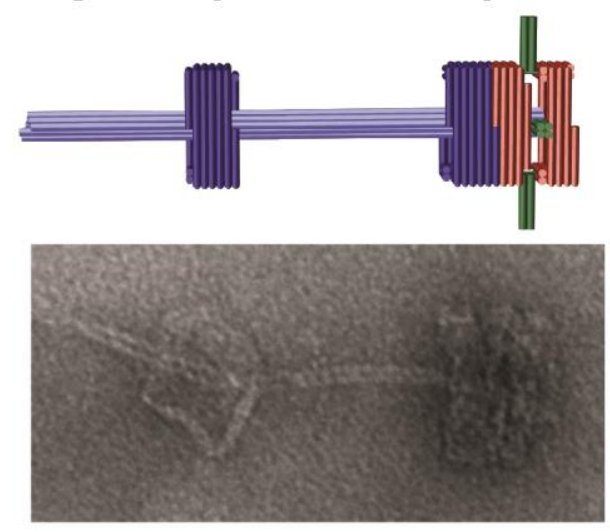

$\mathrm{pR}(\operatorname{ModL})^{*}$
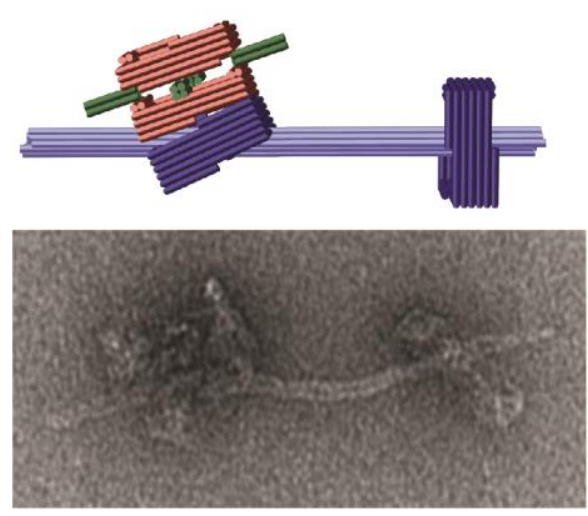

Figure S13. Incorrectly threaded macrocycles in $\mathrm{pR}(\operatorname{ModS}) *$ and $\mathrm{pR}(\operatorname{ModL}) *$ as a result of $\mathrm{dS}$ and $\mathrm{dL}$ bearing an inverted stopper, respectively. Note that misfolded dumbbells with inverted stoppers and excessive macrocycles coexisted in structural switching reactions (Figure $3 \mathrm{~b}$ and c); their docking can lead to the formation of $\mathrm{pR}(\operatorname{ModS})^{*}$ shown here. Correctly formed pseudorotaxanes are shown on the left for comparison purpose. 


\section{rC utilizing $M_{\text {short }}$}

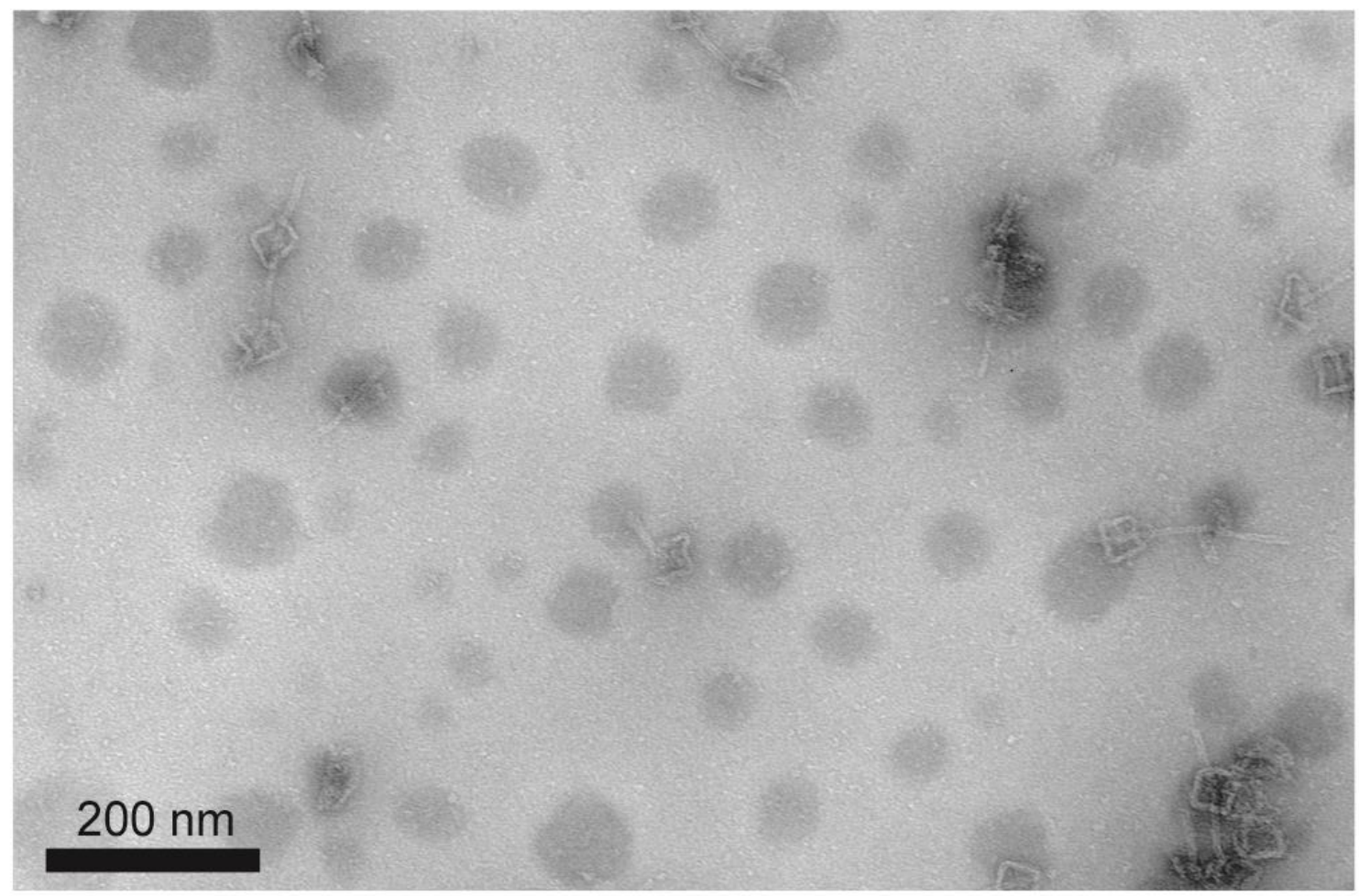

$\%$ of All Particles
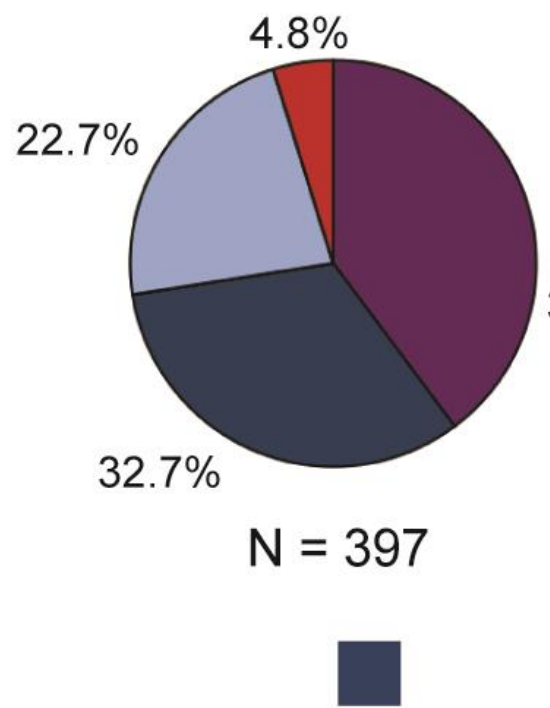

Free $\mathrm{M}_{\text {Short }}$
$\%$ of $\mathrm{M}_{\text {Short }}$ Incorporated
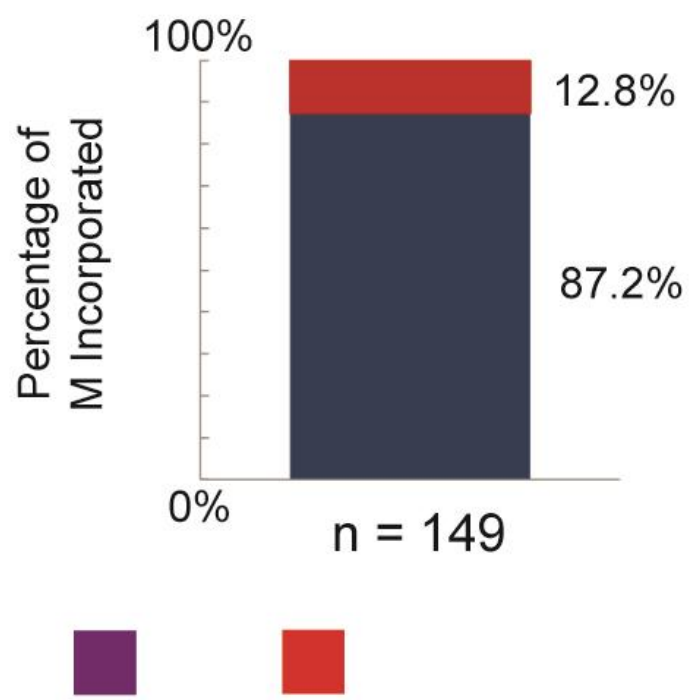

$\mathrm{dS} / \mathrm{dL} \quad \mathrm{R}$

Figure S14. Assembly efficiency of reaction $\mathrm{rC}$ formed with $\mathrm{M}_{\text {Short }}$ under our typical assembly conditions. Rotaxane is produced at levels comparable to the rotaxane design featured in Figures $1-3$. 
References cited in Supporting Information:

1. S. M. Douglas, H. Dietz, T. Liedl, B. Hogberg, F. Graf, W. M. Shih, Nature 2009, 459 (7245), 414-418.

2. S. M. Douglas, J. J. Chou, W. M. Shih, Proc. Natl. Acad. Sci. U S A 2007, 104 (16), 6644-6648.

3. T. Liedl, B. Hogberg, J. Tytell, D. E. Ingber, W. M. Shih, Nat. Nanotechnol. 2010, 5, 520-524. 